\title{
LAS TRAYECTORIAS DEL CAPITAL DE LIDERAZGO DE RODRÍGUEZ ZAPATERO, 2004-2011
}

\author{
Rodríguez Zapatero's leadership \\ capital trajectories, 2004-2011
}

\author{
JOSÉ A. OLMEDA \\ Universidad Nacional de Educación a Distancia \\ jolmeda@poli.uned.es
}

Cómo citar/Citation

Olmeda, J. A. (2021)

Las trayectorias del capital de liderazgo de Rodríguez Zapatero, 2004-2011.

Revista de Estudios Políticos, 191, 247-286.

doi: https://doi.org/10.18042/cepc/rep. 191.09

\section{Resumen}

Siguiendo la conceptualización de capital político de Bennister, 't Hart y Worthy, y su definición del capital de liderazgo como autoridad agregada compuesta de tres dimensiones (habilidades, relaciones y reputación) de un líder, el artículo usa su índice de capital de liderazgo (LCI) para cartografiar sistemáticamente esas tres áreas generales, que combinan medidas concretas con aspectos interpretativos, en los mandatos de Rodríguez Zapatero como presidente del Gobierno. Este índice es más matizado y robusto que la dependencia exclusiva de las últimas puntuaciones de aprobación, y se utiliza como una herramienta para rastrear y comparar sistemáticamente la fortuna política de Zapatero en su gestión de las reformas de políticas públicas (2004-2008) y la crisis económica (2008-2011). El análisis muestra una trayectoria típica de líder meteórico, y que las pérdidas de capital de liderazgo se detectaron principalmente en sus habilidades persuasivas e inspiradoras, y sus relaciones políticas con su partido y la opinión pública.

\section{Palabras clave}

Capital político; índice de capital de liderazgo; presidente del Gobierno; Rodríguez Zapatero; Espańa. 


\begin{abstract}
Following Bennister, 't Hart, and Worthy's conceptualization of political capital, and definition of leadership capital as aggregate authority composed of three dimensions (skills, relations and reputation) of a leader, the article uses their Leadership Capital Index (LCI) to systematically map out those three broad areas, combining concrete measures with interpretive aspects, in Rodríguez Zapatero's mandates as a prime minister. This index is both more nuanced and robust than exclusive reliance on the latest approval ratings, and it is used as a tool for systematically tracking and comparing Zapatero's political fortunes managing policy reforms (2004-2008) and economic crisis (2008-2011). The analysis shows a meteoric leader trajectory, and that leadership capital losses were mainly located in Rodríguez Zapatero's persuasive and inspirational skills, and political relations with his party and public opinion.
\end{abstract}

\title{
Keywords
}

Political capital; Leadership Capital Index; prime minister; Rodríguez Zapatero; Spain. 


\section{SUMARIO}

I. INTRODUCCIÓN. II. LIDERAZGO PÚBLICO, CAPITAL POLÍTICO Y CAPITAL DE LIDERAZGO: 1. Capital político. 2. Capital de liderazgo. III. EL ÍNDICE DE CAPITAL DE LIDERAZGO: OBJETIVOS, FUENTES Y METODOLOGÍA. IV. ¿̇UN LIDERAZGO REDEFINIDOR O REFORMAS POLÍTICAS AL BORDE DEL ABISMO?: 1. Primer mandato de Rodríguez Zapatero: el análisis. V. ¿̇CRISIS? ¿̇QUÉ CRISIS? LA GESTIÓN DE LA CRISIS ECONÓMICA: 1. La gestión de la crisis económica de Zapatero. 2008-2011. VI. CONCLUSIÓN: EVOLUCIÓN Y COMPARACIÓN DEL CAPITAL DE LIDERAZGO DE RODRÍGUEZ ZAPATERO. BIBLIOGRAFÍA.

\section{INTRODUCCIÓN}

Dentro del abanico de transformaciones estructurales de mayores repercusiones de la vida política contemporánea destacan tres que además se hallan estrechamente entrelazadas. Primero, la presidencialización de los regímenes parlamentarios que adquieren rasgos propios de los sistemas presidenciales sin modificaciones de su estructura formal (Poguntke y Webb, 2005) con consecuencias sobre los Gobiernos, los partidos y las campañas electorales. Segundo, la personalización, entendida como el incremento del peso político del actor individual en el proceso político a lo largo del tiempo, mientras que decae el peso del grupo, el partido político, por ejemplo (Rahat y Kenig, 2018: 117). Tercero, la mediatización: los actores e instituciones políticas dependen y están configuradas cada vez más por los medios de comunicación de masas, la televisión especialmente, por la hibridación de medios tradicionales y digitales que configura los sistemas mediáticos contemporáneos; y esto tiene efectos políticos muy notables: refuerzo de la personalización de la política y del liderazgo y la comunicación de su lenguaje como espectáculo y mercadotecnia, lo que provoca, entre otros efectos, un cambio en los procedimientos de selección de las élites políticas (Mazzoleni, 2010: 110-115). Estos tres desarrollos han abonado el terreno para el surgimiento de liderazgos y estrategias populistas (Mazzoleni, 2008: 49-64). El sistema político-administrativo español ha sufrido los efectos de estas mutaciones desde los inicios de la transición democrática y se han acentuado en la etapa de Rodríguez Zapatero (Picarella, 2014; González, 2008; González y Olmeda, 2012).

Como consecuencia de todo ello, entre otros efectos, se ha producido una muy reciente e importante revitalización de los estudios sobre el liderazgo 
político (Bennister, 2012; Helms, 2012; Strangio et al., 2013; Rhodes y 't Hart, 2014; Elgie, 2015; Bennister et al., 2017). Sin embargo, salvo excepciones, buena parte de estas contribuciones se refieren al análisis de las labores del primer ministro en el modelo político-administrativo de Westminster. Aquí se intenta aplicar una de las herramientas conceptuales generada por estas aportaciones, en concreto el índice de capital de liderazgo (ICL) (Bennister et al., 2015) al caso español, y en particular a los dos mandatos del presidente Rodríguez Zapatero.

Tras su inesperado éxito en 2004 (Santamaría, 2007: 31), y después de una legislatura preńada de reformas polarizadoras sin consenso, Zapatero logró una victoria electoral histórica en 2008, pues su respaldo electoral de más de once millones de votos convirtió al PSOE en la formación más votada de la democracia hasta entonces (Montero y Lago, 2010). Durante los inicios de su segundo mandato, fue considerado como un líder visionario indiscutido, con gran popularidad y una imagen pública atractiva. Transmitió poder y control, fue considerado como el mejor activo electoral en su partido y admirado y envidiado por la izquierda en toda Europa (Nash et al., 2008). Pero en el lapso de dos años se convirtió en un líder titubeante, hundido, a merced de las circunstancias, desaparecido durante meses, considerado por sí mismo como un obstáculo para ganar las elecciones. Desde principios de 2011, los barones regionales le criticaron en público hasta el punto de alejarlo $\mathrm{u}$ ocultarlo convenientemente en las campañas electorales para las elecciones regionales y nacionales (Colino y Olmeda, 2012). Años más tarde, su propio partido aún no sabe muy bien si se avergüenza todavía de su legado.

Hasta la fecha, después del estudio seminal de Linz (2009 [1993]) sobre el liderazgo innovador en la transición y en nuestra entonces nueva democracia hay que destacar algunos estudios posteriores que han proseguido esta línea de investigación en diferentes direcciones. Por ejemplo, Natera (2001) elaboró un estado de la cuestión conceptual y ensayó su aplicación al estudio empírico en el ámbito local. Asimismo, Jiménez y Delgado (2016) recogen estudios sobre diferentes líderes políticos del periodo político inicial: los dos primeros presidentes del Gobierno, Suárez y González, junto con otras figuras decisivas como Fernández-Miranda, Fraga, Carrillo, Abril Martorell, Fernández-Ordóńez, Guerra, Pujol y Arzallus. En un plano teórico, Collado et al. (2016) han desarrollado una propuesta con acento sociológico. Jiménez y Peña (2018) examinan a líderes en el poder y en los partidos opositores, con énfasis en las elecciones generales de 2015 y 2016. Igualmente, Rico (2009) estudia en profundidad el impacto electoral de la imagen de los líderes. Además, podría añadirse Picarella $(2009,2014)$, que examina la personalización/presidencialización de los Gobiernos, los partidos y las campańas electorales en nuestro sistema democrático hasta Zapatero. La contribución de este 
trabajo se inscribe fundamentalmente en la dirección abierta por las cuatro primeras contribuciones mencionadas con un enfoque politológico.

Además de sus memorias sobre la gestión de la crisis económica (Rodríguez Zapatero, 2013), o exculpaciones sobre el mismo asunto de uno de sus asociados más cercanos (Solbes, 2013), disponemos de variadas referencias periodísticas. Así, sobre las ideas o personalidad de Zapatero, tenemos biografías hagiográficas como Toro (2007), autorizadas (Campillo, 2001), más templadas (Rodríguez Aizpeolea, 2004) u otras obras menos complacientes o incluso hostiles (García Abad, 2010; González, 2011), pero en su mayoría se referían principalmente a su primer mandato (Papell, 2008). También son interesantes algunos libros sobre su personalidad y actividad política, como Valenzuela (2007), Jaén y Escudier (2007) y Zarzalejos (2011). Sobre su segundo mandato y su gestión de la crisis tenemos Guindal (2012). Análisis más académicos de parte o del conjunto de sus políticas, más o menos ecuánimes, son Bosco y Sánchez Cuenca (2009), Buesa (2010), Field (2011), Martí y Pettit (2010), Sánchez Cuenca (2012) y Colino y Cotarelo (2012). En concreto, el principal trabajo académico que analiza el liderazgo de los hasta entonces presidentes del Gobierno españoles como conjunto, de Suárez a Zapatero, con un enfoque psicosociológico es Álvarez (2014). Específicamente sobre Zapatero hay también distintas contribuciones con un acento sociológico (Jiménez y Collado, 2011; Collado y Jiménez, 2012¹).

Según los observadores, Rodríguez Zapatero pudo explotar y legitimar su considerable poder basado en diferentes cualidades, fue un líder arriesgado, y se basó en la atracción, la persuasión, la simpatía y la seducción, en su liderazgo transformacional al menos en su primer mandato. Según la mayoría de las narraciones, fue un presidente capaz solo para las buenas condiciones meteorológicas, dedicado a su autoimagen y al espectáculo político, buscador de titulares. Pero ¿puede medirse el liderazgo de un presidente del Gobierno? ¿Cómo desempeñó su cargo durante sus dos mandatos? ¿Cómo evolucionaron su trayectoria de liderazgo, su capital político y se vieron afectados por la crisis? ¿Qué componentes del liderazgo se ven más afectados por situaciones excepcionales como las crisis graves y, por lo tanto, son más importantes para la evolución del capital de liderazgo?

Aparentemente, las versiones existentes sugerirían que las repercusiones de la crisis en la pérdida de capital de liderazgo fueron más importantes en el caso de Zapatero que la gestión redefinidora, en expresión de Brown (2014), en su mandato precedente. Este rompecabezas plantea el problema de las

Este texto reproduce casi idénticamente en su totalidad Collado y Jiménez (2011), con los mismos datos. 
relaciones entre la gestión de las crisis por los líderes y la evolución de su capital de liderazgo. Aunque podemos suponer que la crisis generalmente conduce a una percepción de peor desempeño y, por tanto, afecta necesariamente a la pérdida de capital de liderazgo para la mayoría de los líderes, no sabemos mucho acerca de cómo y por qué una crisis afecta a algunos líderes más que a otros, a los que en situaciones similares les va mejor en términos de agotamiento de capital politico.

El artículo se organiza en cuatro secciones. En la primera se clarifica el marco conceptual del análisis y un breve estado de la cuestión de la literatura sobre liderazgo político. En la segunda describimos el ICL y las fuentes para su elaboración. En las dos siguientes se aplica dicho índice a los dos mandatos de Rodríguez Zapatero. Se concluye con un examen sistemático de la trayectoria del capital de liderazgo en ambos periodos.

\section{LIDERAZGO PÚBLICO, CAPITAL POLÍTICO Y CAPITAL DE LIDERAZGO}

Desde un ángulo puramente teórico se suele partir para el análisis del liderazgo político de los presidentes o primeros ministros de la conjunción entre actuación (agency), estructura y personalidad, y su interacción con el contexto, los eventos exógenos como las crisis o los escándalos, junto con el transcurso del tiempo en el cargo. Así, los distintos enfoques hacen hincapié en diferentes aspectos, entre los que cabe distinguir los siguientes (' $t$ Hart y Uhr, 2008: 10-16): centrados en las características del líder; relacionales; institucionales; contextuales; performativos o retóricos, y éticos. El liderazgo público se concibe, por su parte, como un conjunto particular de actividades e interacciones en las que participan personas en posiciones de poder o directivas en un sentido amplio en diversos ámbitos — político, administrativo y cívico- En consecuencia, se señalan un conjunto de funciones que deben efectuarse para que un régimen político se gobierne de manera efectiva y democrática, pero que no se realizan espontáneamente por sus instituciones, organizaciones públicas y rutinas. Así concebido, el liderazgo público evoluciona como una respuesta adaptativa a los desafíos estratégicos, no rutinarios, en una sociedad, que se localizan en tres esferas constitutivas de la gobernación contemporánea que se superponen: la política, la administrativa y la social ('t Hart y Uhr, 2008: 3).

Los líderes del Gobierno son también dirigentes de partidos políticos. En la mayoría de los casos, son líderes de partido mucho antes de que se conviertan en dirigentes del Gobierno. Los partidos políticos desempeñan muchas funciones, una de las cuales es la de movilizar aquellas parcialidades sociales y culturales que apoyan su causa. En este sentido fundamental, los líderes de los 
Gobiernos promueven una mentalidad de nosotros y ellos, contrastando su propio partido político en oposición a los rivales. Pero esta tensión creativa va más allá de las formas corteses de la competencia partidista: los jefes de Gobierno definen con frecuencia su Gobierno, su nación y su sociedad en términos de un conjunto de diferencias entre nuestro mundo y otros mundos, tratando de reforzar un sentido de identidad nacional o social, resaltando las diferencias o contrastes gestionados por los líderes en competencia.

No solo los jefes de Gobierno, sino todos los líderes políticos tratan la definición de cuáles son los problemas por resolver, que es otra manera de decir que también pueden impulsar su negación. Esta forma de liderazgo se ilustra en las posturas de los líderes políticos que compiten por los riesgos que plantea el cambio climático: algunos son rotundos en su negación, mientras que otros abrigan temores inminentes. Cada líder político aspirante ve oportunidades para el cambio de políticas públicas, incluso si está convencido de que es más fructífero hablar tranquilizadoramente de continuidad en vez de cambio. Los líderes políticos persiguen las responsabilidades del poder con mayor o menor aceptación de la carga de la rendición de cuentas pública. El liderazgo implica el equilibrio entre las servidumbres de la gobernación con las responsabilidades del cargo: el aprovechamiento de las iniciativas de política pública que vienen con el poder del Estado a sabiendas de que una variedad de juicios públicos llegará por vía electoral. Generalmente se considera la gestión de las crisis como la gran prueba del liderazgo y ello tanto en el sentido de que las resuelvan como en el de que traten de utilizarlas en su favor ('t Hart y Uhr, 2008: 3-10).

Sin embargo, aquí interesa un liderazgo público específico, el que ejercen quienes encabezan el poder ejecutivo de los regímenes presidenciales o parlamentarios. ¿Cómo podemos valorar la labor de los presidentes o de los primeros ministros? La evaluación comparativa de los líderes políticos en su contexto resulta una materia poco tratada en la literatura. No obstante, cabe mencionar algunas aportaciones de interés tras las contribuciones fundacionales de Burns (1978) y Blondel (1987). Elgie (1995) es el pionero de los estudios comparativos al analizar el fundamento institucional del liderazgo en Gran Bretaña, Francia, Alemania, Estados Unidos, Japón e Italia. Tiempo después ha retomado el análisis del liderazgo empleando distintos enfoques epistemológicos y ontológicos (Elgie, 2015). También desde una óptica institucional, Helms (2005) ha desarrollado el planteamiento más ambicioso al comparar los casos de Estados Unidos, Reino Unido y Alemania, centrándose en la dimensión más propiamente política del liderazgo, es decir, la movilización de apoyo para un programa dado. La otra dimensión del liderazgo se refiere al contenido real de la política pública (policy) impulsada. Su esquema analítico descansa sobre tres elementos que configuran las variables determinantes para el desempeño del liderazgo ejecutivo: las personalidades de quienes 
ocupan el cargo supremo, las instituciones que determinan el espacio de maniobra en el que el presidente o primer ministro ejerce sus atribuciones y las variables circunstancias que acompañan su estancia en el poder. Otro estudio comparativo reciente es el de Bennister (2012), quien examina los casos de Gran Bretaña bajo Blair y Australia bajo Howard. Este autor aúna también los factores personales e institucionales. Su marco de referencia respecto a la primera faceta atiende a variables como los atributos del líder (carácter, cualificaciones); la relación con el partido (su prestigio o reputación); el perfil público, y la personalización de las campañas electorales. Con relación al segundo aspecto, Bennister destaca el papel como cabeza legal del Gobierno, como controlador del núcleo del Ejecutivo, como líder del gabinete, por ser quien establece la agenda en tanto que gestor de los medios informativos y como líder del partido al ser primer ministro.

Una contribución diferente, utilizada para evaluar el rendimiento presidencial en los Estados Unidos, es la influyente elaboración de Greenstein (2000), que trata de valorar el estilo de liderazgo, el carácter y las cualidades políticas y personales de los ocupantes de la Casa Blanca: su competencia en tanto comunicadores públicos, su capacidad organizativa, su habilidad política, el extremo en que están imbuidos de una visión propia de las políticas públicas, el estilo cognitivo con el que procesan la cascada de asesoramiento e información que les llega, su inteligencia emocional, de manera que administre sus emociones y las vuelque en propósitos constructivos. Este enfoque se ha aplicado a primeros ministros británicos en general (Theakston, 2017), a casos concretos como Wilson (Honeyman, 2007) o Brown (Theakston, 2011), o a los presidentes franceses (Chamorel, 2003).

De otra parte, la influyente contribución de Skowronek (1993, 2008) analiza sistemáticamente la relación entre las habilidades de los líderes y los cambios económicos y sociales más amplios a través de las pautas de comportamiento presidencial en los Estados Unidos. En su análisis contextual o situacional, las similitudes del liderazgo se repiten a lo largo del tiempo político en que los líderes se encuentran. Utiliza sistemáticamente esta teoría para trazar las posibilidades y las limitaciones que afronta el liderazgo de cada titular de la Presidencia, para explicar así su éxito o fracaso según la concordancia entre la estructura de oportunidades del contexto y el papel de las concepciones y posturas políticas individuales. La identidad política de los titulares puede ser de oposición o de apoyo a un régimen; los compromisos y valores previamente establecidos determinan los modos de liderazgo de los líderes. Cuando un régimen es resistente, las oportunidades de los líderes que se oponen a él son limitadas. En contraste, cuando un régimen es vulnerable, el establishment político es incapaz de resolver los problemas emergentes y la crisis y, en consecuencia, pierde el apoyo público en forma de credibilidad y legitimidad. Este 
entorno político crea un mayor espacio para que los líderes opositores obtengan autoridad y recreen el orden político a su favor. Por lo tanto, el éxito o el fracaso de los líderes depende significativamente de la fuerza con la que resuenen en el entorno político en el que operan.

Dos contribuciones recientes merecen reseñarse con brevedad. Strangio et al. (2013) desarrollan una perspectiva comparativa centrada también en los sistemas de Westminster, pero orientada a la valoración de su actuación determinada por la interacción entre factores personales, institucionales y contextuales. Por su parte, Rhodes y 't Hart (2014) han compilado el tratamiento interdisciplinar más exhaustivo hasta la fecha sobre el liderazgo político, pues atiende tanto a las distintas tradiciones analíticas y metodológicas como a las diferentes perspectivas de su funcionamiento real, y proporciona también una perspectiva comparativa completa que incluye casos de una gran variedad de sistemas político-administrativos.

\section{CAPITAL POLÍTICO}

La primera referencia que conozco sobre la noción de capital político la proporciona Almond (1969) en su pionera conceptuación del paradigma de desarrollo político para aludir al rendimiento del sistema político, su capacidad simbólica para la creación o consumo de sus reservas, su capital. La diferencia entre sistemas en este plano provendría de las distintas tasas de acumulación o utilización de estas. Almond (1969: 464) subraya que «incluso para los sistemas políticos contemporáneos es difícil separar los procesos que contribuyen o agotan estas reservas de capital político. Y, sin embargo, el comportamiento de los sistemas políticos bajo tensión, su capacidad para hacer frente a las crisis depende en gran medida de la disponibilidad de estas reservas».

Posteriormente, 't Hart (2014) y Bennister et al. (2015) parten de la conceptuación de Bourdieu (1986) sobre las tres formas fundamentales de capital —económico (dinero y propiedades), cultural (bienes y servicios culturales, incluyendo las credenciales educativas) y social (contactos y redes) para elaborar su aportación. Bourdieu añadió posteriormente el capital político, una manifestación menos desarrollada que las otras tres formas de capital que había presentado inicialmente, en su examen de la representación política en su teoría del campo político. Lo describió como (1991: 192): «El capital político es una forma de capital simbólico, crédito basado en la credibilidad o creencia y reconocimiento o, más precisamente, en las innumerables operaciones de crédito por las cuales los agentes confieren a una persona (o a un objeto) los poderes que reconocen en él (o en ello)».

Las ideas de Bourdieu nos permiten identificar tres aspectos clave sobre la naturaleza del capital político. En primer lugar, es crucial tener habilidades 
para llegar a ser y continuar siendo un líder político. El proceso de ascendiente que constituye el liderazgo comienza cuando los políticos individuales hacen uso de sus formas de capital con el fin de ganar pugnas y avanzar dentro de la jerarquía política para alcanzar el poder, la creación de una imagen y un camino distintivos. De esto se deduce que el liderazgo consiste en una lucha continua para mantener su ascendiente.

En segundo lugar, el capital político es relacional. Bourdieu vio el poder político como algo derivado por los políticos de la confianza por parte del público (expresada como una forma de crédito), como una capacidad para movilizar. Esto conecta el capital político con las percepciones del público, con los medios de comunicación como una pieza crucial entre los dos.

En tercer lugar, para Bourdieu los escasos niveles de interés del público en el proceso político significan que el capital político se convierte en un propósito centrado en las élites, los líderes y los partidos con la política concentrada en las manos de los políticos profesionales y burócratas, lo que le conduce a identificar el capital político solo entre los líderes o partidos políticos. Una vez que se adquiere, el capital se convierte en parte de un ciclo de reputación, un proceso recíproco en el que los líderes presentan ideas, realizan acciones y consiguen que se hagan las cosas. El capital político es impugnado así continuamente y se disputa por los medios de comunicación, el público y los políticos. El capital político es dinámico y contingente y puede conservarse solo a costa del trabajo incesante que es necesario para acumular crédito y evitar el descrédito ante el tribunal de la opinión pública. Otras contribuciones de interés sobre esta noción y otras conexas, basadas en distinto grado en la aportación de Bourdieu, son Alcántara (2017), French (2011), González (2005) y Joignant (2012, 2019).

López (2002) efectúa independientemente una distinción complementaria sobre dos aspectos: el capital político representativo y el reputacional. El primero se definiría por los atributos que determinan la productividad en la influencia sobre la política pública, y se fundamenta en la experiencia gestora o parlamentaria, la extensión de los contactos políticos y organizativos, la perspicacia legislativa y su capacidad manipuladora. El segundo lo haría por los atributos que determinan la posición frente a los votantes y a otros intereses desorganizados, y se basa en su afiliación partidista, su historial parlamentario, su programa electoral y su reconocimiento nominal por el público. Son interdependientes, en ocasiones mutuamente excluyentes y se refuerzan en otros casos; a veces, la acumulación de uno implica la pérdida del otro.

\section{CAPITAL DE LIDERAZGO}

Es importante diferenciar entre el capital político y el capital de liderazgo. El capital político se asocia con los lazos horizontales de redes, relaciones y 
confianza que se heredan, se acumulan y se cultivan con frecuencia para obtener crédito político vertical. El capital de liderazgo puede recurrir a esos fundamentos horizontales, pero solo se aplica a quienes ocupan posiciones de liderazgo. Se centra más en cómo confieren autoridad los electores a un cargo público particular, que luego lo utiliza. Evoluciona desde y en paralelo con las atribuciones asociadas a las cualidades personales de estos titulares de cargos, es decir, su percepción de la competencia, la integridad y la capacidad para el liderazgo. Dependiendo de cuán firme y ampliamente se comparten esas percepciones en un sistema político, el capital de liderazgo del titular de un cargo se puede acumular o agotar. Como tal, no es un atributo personal de un líder, sino un espacio garantizado socialmente en el que pueden ejercer el liderazgo como se ha definido anteriormente. Kane (2001), por ejemplo, ha vinculado el capital de un líder con el establecimiento de una autoridad moral.

La noción de capital de liderazgo nos permite ver la diferencia entre estar en el cargo y estar en el poder. En la política contemporánea, se considera que los líderes tienen cada vez más protagonismo, pero también están más constreñidos y son más vulnerables. El estudio del liderazgo político mediante la lente del capital de liderazgo presupone que es la interacción dinámica entre las habilidades individuales y las condiciones contextuales lo que da forma a la destreza de los líderes para actuar y determina su legado. 't Hart (2014) y Bennister et al. (2015) definen el capital de liderazgo, entendido como el grado en que los responsables políticos pueden alcanzar y ejercer con eficacia la autoridad, y se compone de tres dimensiones: las habilidades, las relaciones y la reputación de un líder (véase el gráfico 1). El capital de liderazgo sube y

Gráfico 1. Los componentes del capital de liderazgo

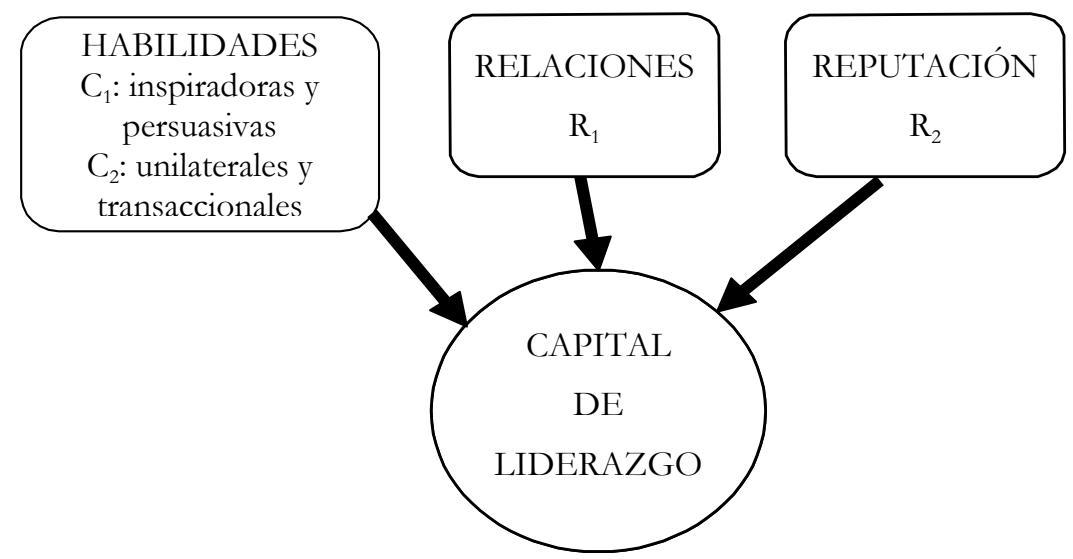

Fuente: 't Hart (2014: 64), Bennister et al. (2015: 422). 


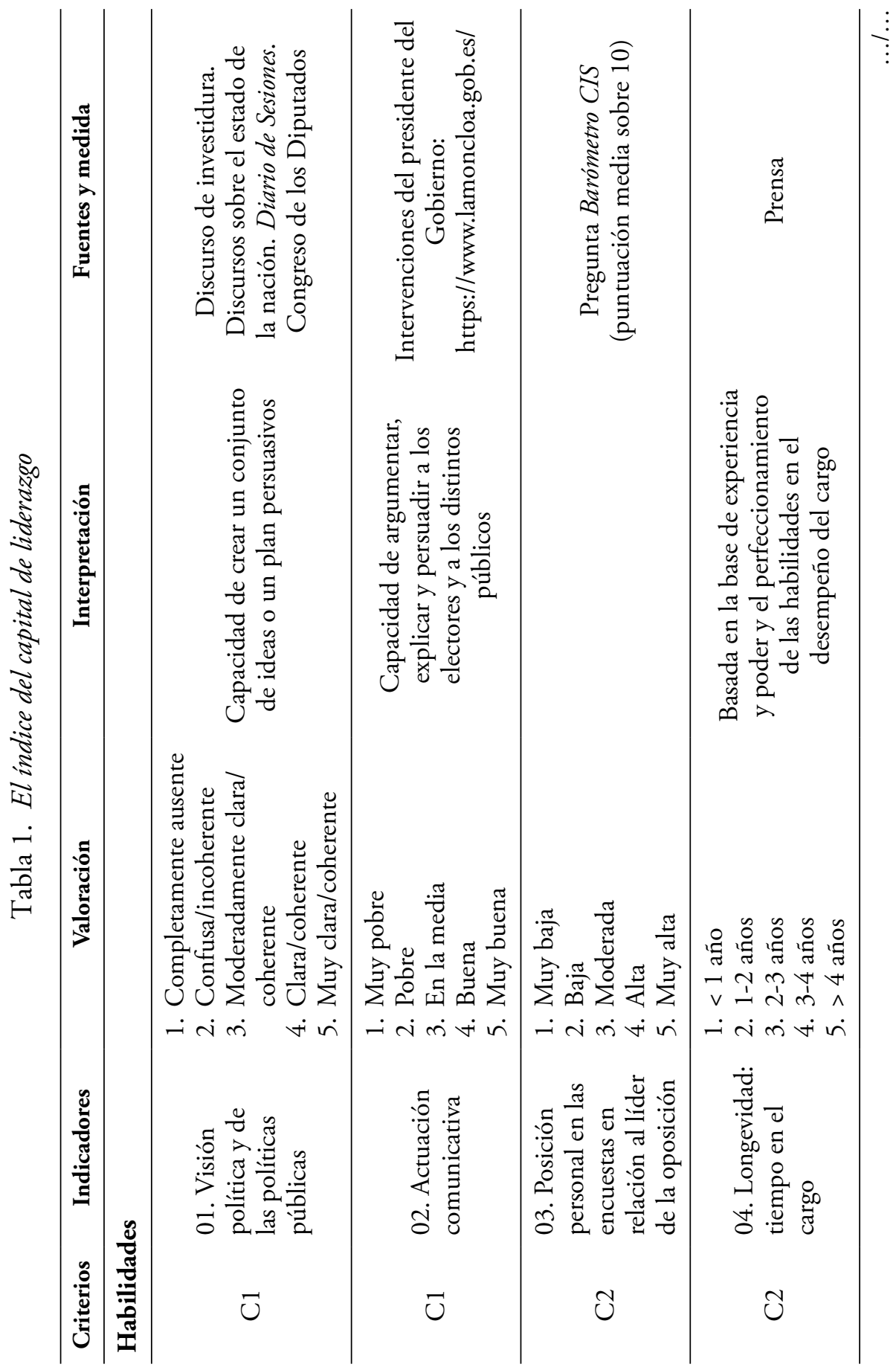



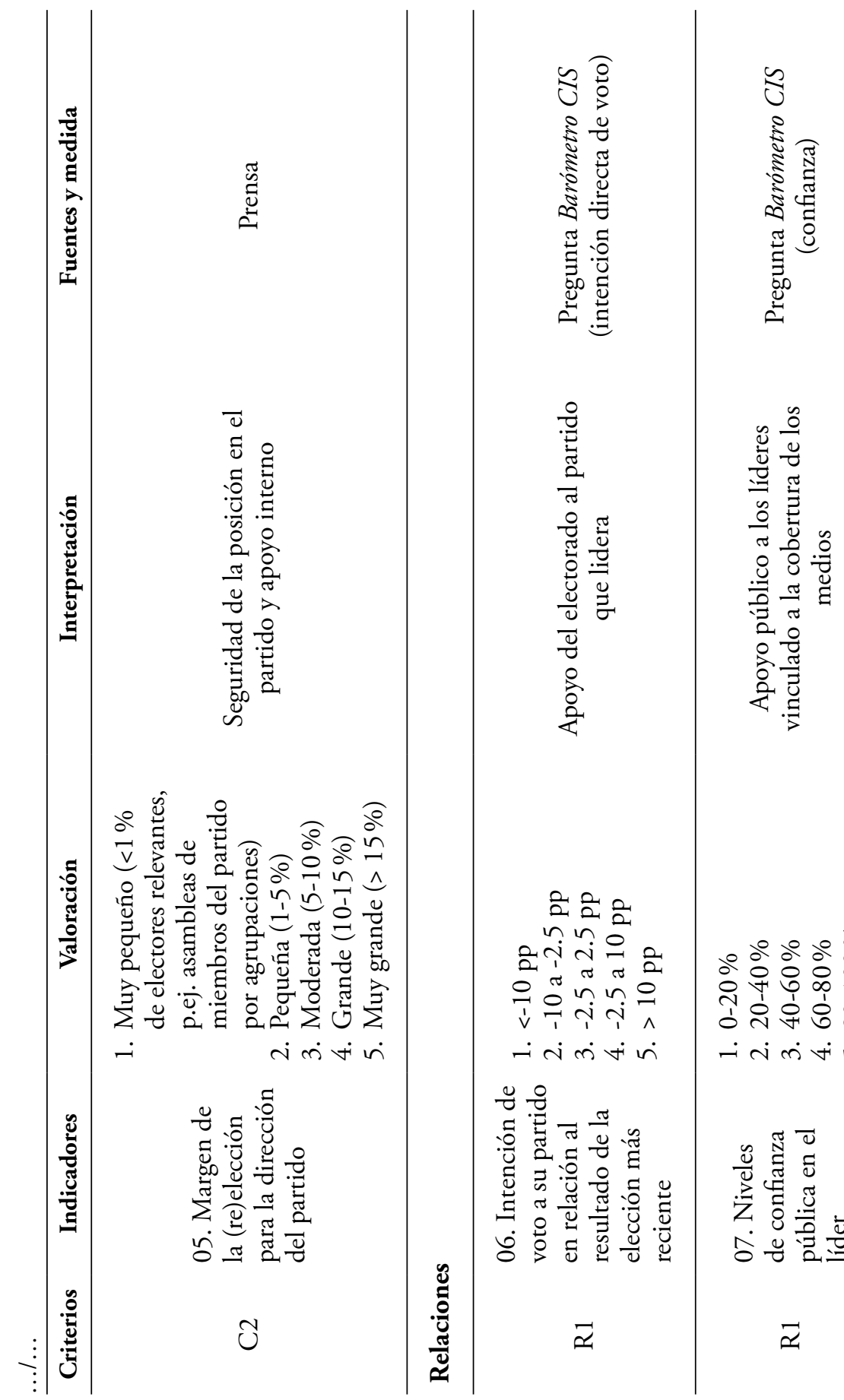

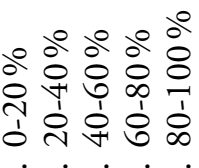

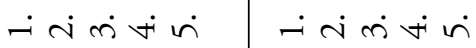

음

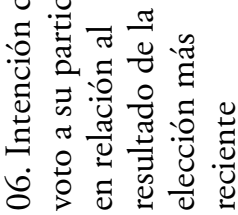

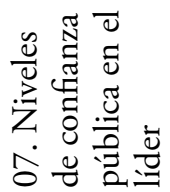

$\not{1}$

$\not$ 


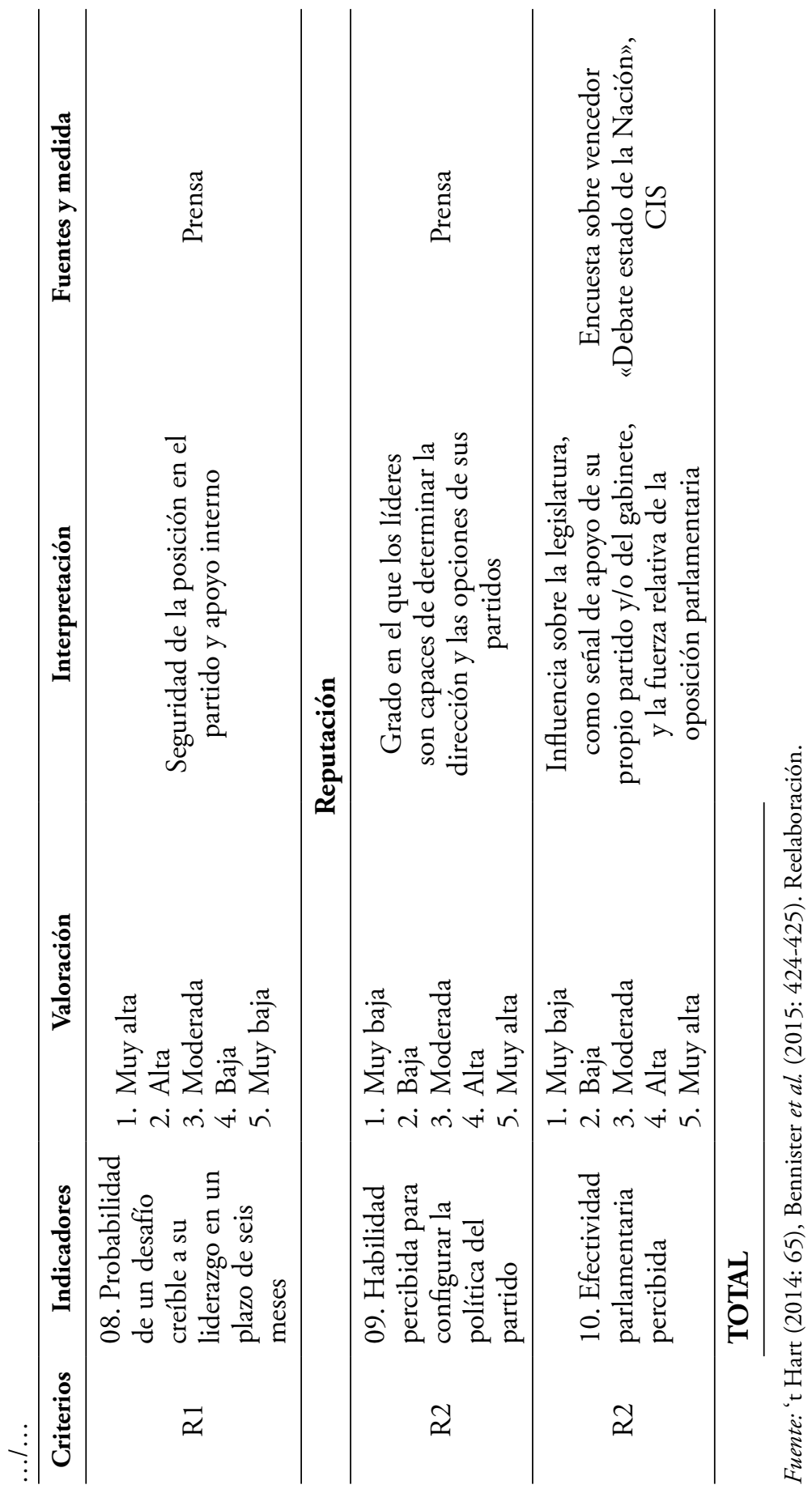


baja con el tiempo dentro de una trayectoria inevitable normalmente de adquisición, gasto y disipación. Presentan un índice del capital de liderazgo (ICL) que asigna sistemáticamente esas tres grandes áreas que combinan medidas concretas con aspectos interpretativos. Este índice sintético (véase la tabla 1) puede usarse como una herramienta para el seguimiento y la comparación de la fortuna política de los líderes de una manera sistemática que es a la vez más matizada y robusta que la dependencia exclusiva de los últimos índices demoscópicos de aprobación o popularidad.

\section{EL ÍNDICE DE CAPITAL DE LIDERAZGO: OBJETIVOS, FUENTES Y METODOLOGÍA}

Como el caso español parece mostrar, en algunos casos y en circunstancias de crisis muy similares, los líderes que comienzan con un capital de liderazgo más alto pueden verse más afectados por la crisis y su liderazgo que otros sin mucho capital inicial. Es como si aquellos con mayor capital tuvieran mucho más que perder y aquellos con un capital bajo-medio pudieran superar la crisis más fácilmente. ¿Es el tipo de líder o las dimensiones de liderazgo predominantes en cada caso lo que explica esto? ¿Son las habilidades, las relaciones y la reputación igualmente necesarias para sobrevivir en situaciones de crisis y mantener ese capital? ¿Qué componentes del capital de liderazgo parecen sobrevivir mejor y son más importantes para la gestión de las crisis? ¿La visión de las políticas, la confianza pública o el control de su propio partido son los aspectos más importantes para un líder que afronta la gestión de las crisis? Y ¿se ven afectados de manera diferente por los requisitos de la gestión de las crisis?

Para explorar estas cuestiones y tratar de responder estas preguntas se utilizarán los conceptos y las dimensiones del índice de capital de liderazgo (ICL), propuesto por 't Hart (2014: 60-71) y Bennister et al. (2015) de la tabla 1 . Se parte de las hipótesis de que hoy en día parece que las habilidades de los líderes y la visión política tienen menos prioridad que las relaciones de confianza y las percepciones públicas para determinar su mantenimiento y supervivencia. Por otra parte, en las situaciones de crisis las políticas de respuesta generadas globalmente están más o menos determinadas o impuestas desde el exterior y su efectividad generalmente está fuera del control del líder, y siempre existe la posibilidad de evadir la culpa al transferirla a otros factores y reclamar el crédito por cualquier mejora. Por esa razón, para mantener el capital de liderazgo propio puede ser más importante salvaguardar cierta capacidad para fomentar un mínimo de popularidad y defender un control incuestionable del propio partido. Eso explicaría que a veces los líderes que no tienen una visión de política coherente o un buen desempeño comunicativo podrían 
compensar esta deficiencia con buenas relaciones y reputación entre los suyos. Esto también explicaría que, en situaciones de crisis, los líderes con un alto capital de liderazgo basado en habilidades y desempeńo comunicativo pueden agotar su capital más rápidamente que aquellos con un capital reducido, pero basados principalmente en las buenas relaciones y el control de su partido.

Para responder a estas preguntas y comprobar estas hipótesis, creemos que es útil comparar diacrónicamente el liderazgo ejercido por Zapatero en su primer mandato y durante la crisis. El objetivo central de este artículo es describir su trayectoria de liderazgo utilizando el ICL para mostrar cómo ha adquirido y utilizado ese capital al lidiar con la gobernación en condiciones favorables en su primera legislatura, y con la deuda soberana y la recesión con la crisis fiscal en España producida por la crisis financiera mundial de 2007-2008 en la segunda. Nuestro objetivo es abordar la cuestión del liderazgo utilizando un conjunto de dimensiones medibles y comparables, para proporcionar una primera exploración sistemática de las características del liderazgo de Zapatero. De esta manera, las instituciones ejecutivas, el diseño institucional de su cargo y su identidad política se mantienen constantes, por así decirlo. Pero gobierna frente a un contexto cambiante, constreñido estructuralmente por la pertenencia a la zona euro dentro de la Unión Europea, y la variación está en las diferentes contingencias de la gobernación y los componentes principales de su capital de liderazgo.

Para analizar la trayectoria del capital de liderazgo se observan tres instantáneas en cada una de sus legislaturas: en la primera, el momento inicial con la victoria electoral (marzo de 2004), la aprobación del Estatuto de Cataluña (abril de 2006), y después de las elecciones municipales (abril de 2007); en la segunda, la victoria electoral (marzo de 2008), el reconocimento de la crisis (junio de 2010), y tras la convocatoria anticipada de elecciones generales (septiembre de 2011). Gracias a este diseño se efectúa una comparación sistemática entre ambos mandatos y se concentran las posibilidades explicativas de los posibles hallazgos del estudio. Los datos recogidos provienen del Diario de Sesiones del Congreso de los Diputados, las intervenciones del presidente del Gobierno recogidas en www.lamoncloa.gob.es, los Barómetros y otros estudios del CIS, y la consulta de las hemerotecas digitales de dos de los principales diarios españoles (La Vanguardia y El País, 2004-2011).

\section{IV. ¿̇UN LIDERAZGO REDEFINIDOR O REFORMAS POLÍTICAS AL BORDE DEL ABISMO?}

El contexto político que rodeó las elecciones generales del 14 de marzo de 2004 sugirió una expectativa general de una victoria clara para el PP, pero 
en el penúltimo día de la campańa electoral que finalizaría el 14 de marzo de 2004, se perpetraron atentados terroristas en Madrid. 192 personas murieron y 1430 resultaron heridas. Tres días antes de las elecciones generales, el gobernante Partido Popular (PP) se había adelantado en las encuestas en 5 puntos porcentuales y el sucesor designado de Aznar, el exministro del Interior y vicepresidente Rajoy, parecía casi seguro vencedor. Sin embargo, después de los ataques el PP cayó del 43 en las encuestas al $36 \%$ de los votos del domingo, un cambio de 7 puntos porcentuales y el desencadenante de su pérdida del Gobierno, pasando directamente de la mayoría absoluta a la oposición sin etapa de Gobierno en minoría. La oposición socialista liderada por Rodríguez Zapatero obtuvo así una victoria histórica. La victoria del PSOE no fue anticipada por las encuestas, excepto por la consultora Noxa (Santamaría, 2007), y fue fruto de un conflicto de encuadres y culpabilización (Olmeda, 2008). También hubo una victoria socialista en las elecciones regionales simultáneas en Andalucía, que aumentó sus escańos en el Parlamento regional.

\section{C1. Visión y comunicación}

El presidente del Gobierno es responsable personalmente ante la opinión pública y se identifica con sus prioridades políticas al proporcionar su presentación en los medios de comunicación y también sufrir las consecuencias negativas de su fracaso ante los ciudadanos. Este es el caso de algunas iniciativas de política exterior en el primer mandato de Rodríguez Zapatero, como la retirada de las tropas españolas en Iraq y también en varios asuntos como la alianza de civilizaciones, la recuperación de la memoria histórica, la reforma del Estatuto de Cataluña o la negociación con la organización terrorista ETA encuadrada como proceso de paz. En el primer mandato, la visión y las prioridades de Zapatero tenían que ver con esos temas y otras políticas con una base más ideológica de orientación social diferente como medidas contra la violencia doméstica (2004), igualdad entre mujeres y hombres (2007), dependencia (2006), consideración de matrimonio y derechos de adopción a las uniones homosexuales (2005) y la regularización masiva de inmigrantes indocumentados (2005).

Las relaciones del primer ministro con los medios son cruciales para un enfoque realista del proceso político en las democracias contemporáneas, que se caracterizan a este respecto por su mediatización (Mazzoleni, 2010: 51-59; Helms, 2008). El modelo de medios y política que prevalece en España se llama pluralismo polarizado o mediterráneo en la tipificación de Hallin y Mancini (2004). Las implicaciones prácticas de este modelo son bien conocidas. Primero, destaca el predominio de la cobertura negativa; esto significa que hay un alto grado de negatividad en los medios de comunicación españoles, ya que se muestran muy pocas noticias favorables a uno de los actores 
de la información relacionada, con editoriales desfavorables y alineados políticamente. Como los medios solo critican a los antagonistas, su función de vigilancia se diluirá, ya que se da por supuesto que ataca al oponente. En lugar de argumentación y discusión, el público se ha acostumbrado a las acusaciones de la oposición ritual que no apelan a la deliberación racional, sino a pistas emocionales e ideológicas para la identificación con cualquiera de las facciones contendientes. En consecuencia, los argumentos racionales y el debate de ideas son reemplazados por un periodismo de trinchera cuya agresividad y negativismo solo se comparan con su laxitud y permisividad, dada su falta de compromiso con las reglas más básicas de equidad y fuentes de información contrastantes. Zapatero tuvo un buen desempeño comunicativo en este entorno mediático y tomó la iniciativa ante los medios de difusión (véase el gráfico 2).

\section{Gráfico 2. Entrevistas con Rodríguez Zapatero en radio y televisión 2004-2008 y 2008-2011}

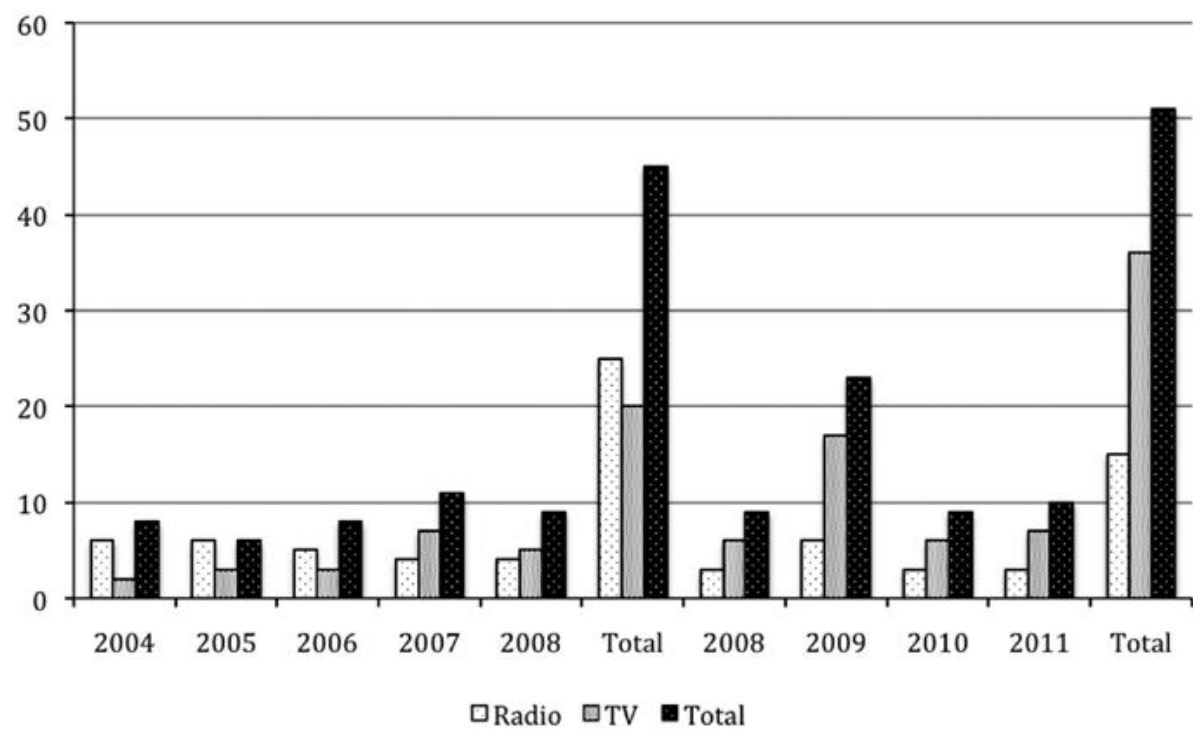

Fuente: http://www.lamoncloa.gob.es.

\section{C2. Sondeos, permanencia y elección}

Rodríguez Zapatero, líder del PSOE en 2004 —su lema: «ZP Zapatero presidente» (Campmany, 2005; Montero et al., 2007)—, consiguió 11026163 votos $(42,6 \%)$ y 164 escaños en las elecciones generales de 2004, después de los 
ataques terroristas del 11 de marzo en plena campaña (Montero y Lago, 2007). El PP obtuvo 9763144 votos y 148 escaños. La gente se agolpó esa noche electoral ante la sede de Ferraz, gritando: «№ nos falles! ¡No nos falles!» (Rico, 2007). Zapatero fue investido presidente del Gobierno en la primera votación con 183 de los 350 diputados: a favor el Grupo Socialista, IU, ERC, CC, BNG y ChA; 148 en contra (PP) y 19 abstenciones (CiU, PNV, EA y NaBai).

Después de su primera victoria electoral, en lugar de gravitar hacia partidos nacionalistas entonces de oposición semileal (PNV y CiU) como hizo González en el pasado cuando la situación requería que ganara el centro político, Zapatero realizó un cambio estratégico hacia las fuerzas que formaron el primer tripartito catalán, en el poder desde diciembre de 2003, que había firmado el Pacto del Tinell para la exclusión del PP de los acuerdos políticos en Cataluña y en el resto de España. Lo hizo en parte por convicción y en parte influido por Maragall y el PSC, que lo habían apoyado en el XXXV Congreso del PSOE contra Bono. Entonces se cimentó una coalición, primero en Cataluña y luego en el Congreso, que incorporó fuerzas antisistema, en el sentido técnico, como ERC, opuestas a la monarquía constitucional y a favor de la secesión, o los ecosocialistas ICV que también defendían la autodeterminación de Cataluña. En cualquier caso, estas fuerzas políticas estaban lejos de

Gráfico 3. Valoración personal de Rodríguez Zapatero con relación al lider de la oposición (media sobre 10), 2004-2007 y 2008-2011

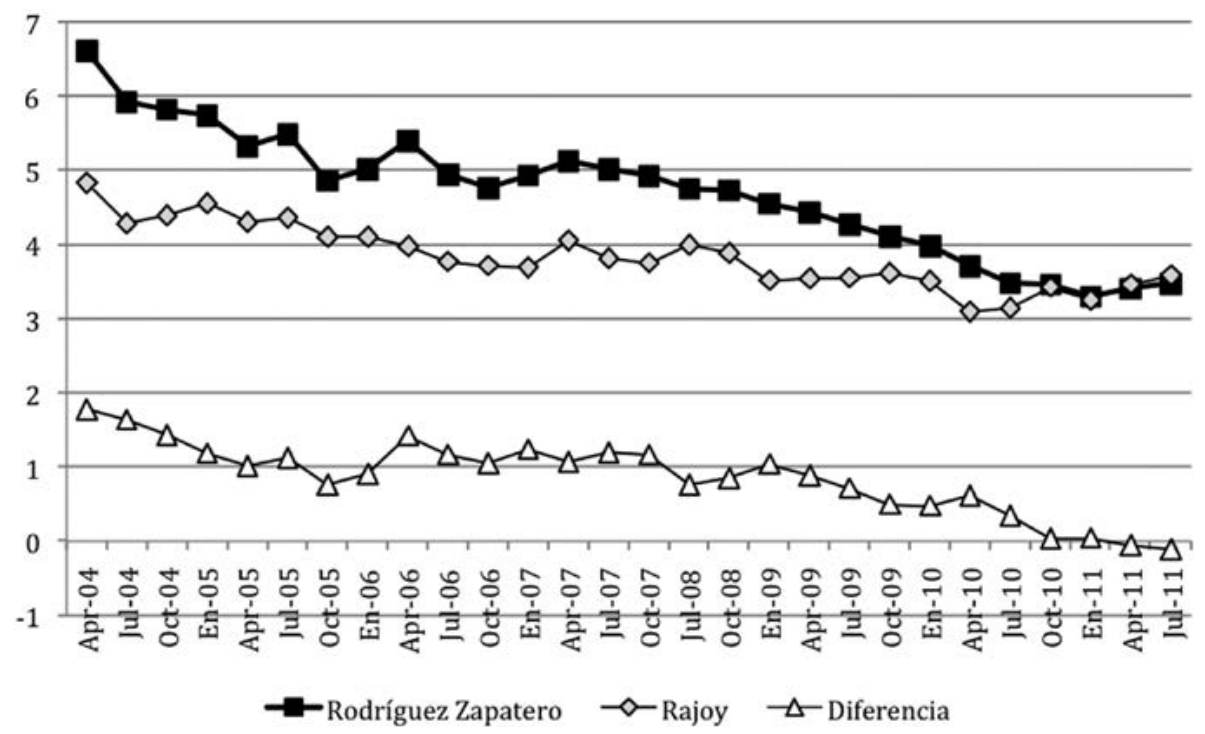

Fuente: CIS.es. 
los electorados ideológicos socialistas en Cataluña y, especialmente, en el resto de España. Entonces, en lugar de incorporar estas fuerzas al sistema, deshabilitando sus enfoques antisistema, Zapatero perdió el equilibrio, desaprovechó el centro político para el nuevo Gobierno socialista y, aunque quizá favoreció su victoria electoral en 2008, esta fue menor de lo esperado debido a esta alineación política (González y Bouza, 2009: 169-193).

Tras su triunfo electoral completó los cuatro años de mandato siempre por encima de Rajoy, el líder de la oposición, en las evaluaciones personales en las encuestas, como puede verse en el gráfico 3. Siempre lo hizo por más de un punto, excepto en dos encuestas de 2005 y 2006. Así, aunque fue perdiendo lentamente popularidad, su oponente lo hizo con mayor rapidez. Había ganado las elecciones para la dirección del PSOE por un margen muy pequeño (solo 9 votos más que Bono, su futuro ministro de Defensa) (Méndez, 2006). Después de eso, comenzó a limpiar el partido de sus oponentes. Rodríguez Zapatero terminó primero con las facciones internas, origen de amargas disputas entre guerristas y renovadores, y luego su tarea principal fue consolidar su liderazgo en la organización, aspecto en el que era un experto por su experiencia en la conflictiva estructura organizativa en León.

\section{R1. Sondeos, confianza y desafío}

La pérdida de apoyo electoral en intención directa de voto para el partido socialista promedió 9 puntos porcentuales, y siempre mantuvo una diferencia significativa con el Partido Popular superior a 7 puntos porcentuales (véase el

\section{Gráfico 4. Intención directa de voto con relación al resultado electoral más reciente, Zapatero (PSOE): 2004-2008-2011}

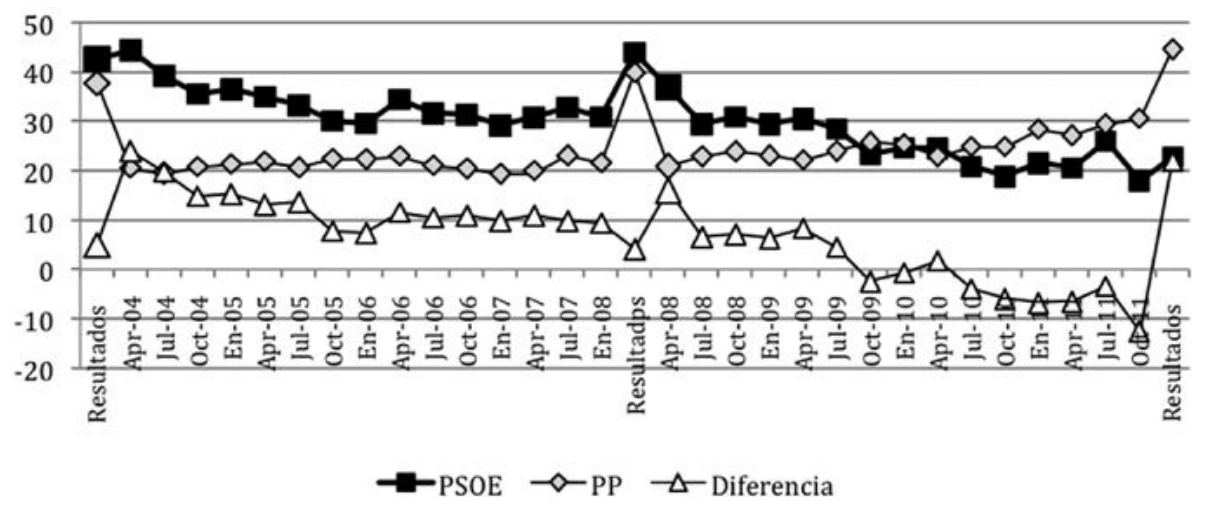

Fuente: CIS.es. 
gráfico 4). A su vez, Zapatero disfrutó de una larga luna de miel de siete meses con un nivel de confianza del público superior al $50 \%$, comenzando luego una lenta decadencia. Paulatinamente, la desconfianza pública sobre él fue creciendo, y llegó a casi un $60 \%$ al final de su primer mandato quizá como resultado de sus imprudentes iniciativas unilaterales sobre la política antiterrorista y la reforma del Estatuto catalán (véase el gráfico 5). El ataque terrorista de ETA en diciembre de 2006, que puso fin al alto el fuego y asesinó a dos personas, no pareció tener una gran influencia en la opinión pública.

Gráfico 5. Niveles de confianza del público en Rodriguez Zapatero, 2004-2008-2011

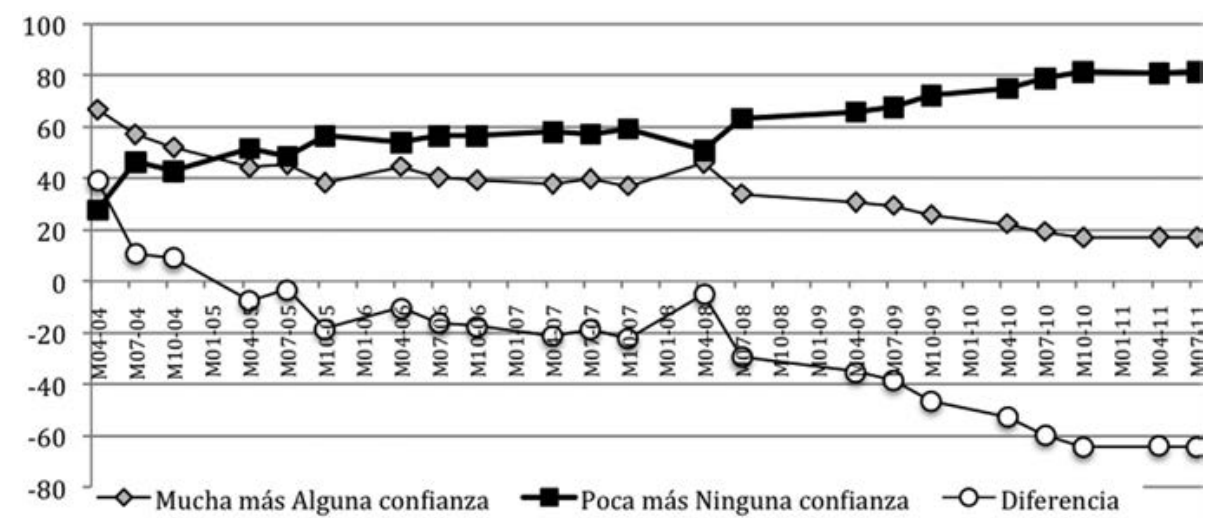

Fuente: CIS.es.

El componente clave de cualquier evaluación del capital de liderazgo de Rodríguez Zapatero es la ausencia de un rival creíble en el partido socialista en sus dos mandatos. El resultado de la gestión partidaria de Zapatero, en términos ideológicos y organizativos, para la que ha disfrutado de un poder sin precedentes en comparación con los líderes anteriores, es doble. Por un lado, sin duda calmó los conflictos internos que siguieron a la marcha de Felipe González, la victoria en las primarias de Borrell y su renuncia posterior, y la derrota de Almunia en 2000, pero con la contrapartida de la desaparición de la crítica, la reflexión y la disidencia, en una palabra, del debate político y la vida interna, así como de cualquier figura política alternativa a su liderazgo en el PSOE. Esto pudo contribuir al colapso socialista en las elecciones de noviembre de 2011 (Méndez, 2006; Delgado y Cazorla, 2017). 


\section{R2. Políticas públicas y Parlamento}

Zapatero fue un primer ministro con una gran capacidad para dar forma a la política pública. Impulsó propuestas muy arriesgadas: el nuevo Estatuto de Autonomía de Cataluña o la negociación con ETA, la memoria histórica de la Guerra Civil y la dictadura franquista, que sirvieron como disparadores de la polarización. Además, estableció una agenda orientada a cuestiones de igualdad de género y estilo de vida (feminismo de Estado, uniones homosexuales, derechos de los transexuales) y nuevos problemas sociales (dependencia de mayores o discapacitados, inmigración). Su partido le siguió, aunque estos asuntos estaban muy lejos del programa socialista tradicional. Pero abordó estos problemas con un Gobierno minoritario, excluyendo al principal

Gráfico 6. Ganador de los debates sobre el estado de la nación, 2005-2011 (porcentaje de entrevistados que lo afirman)

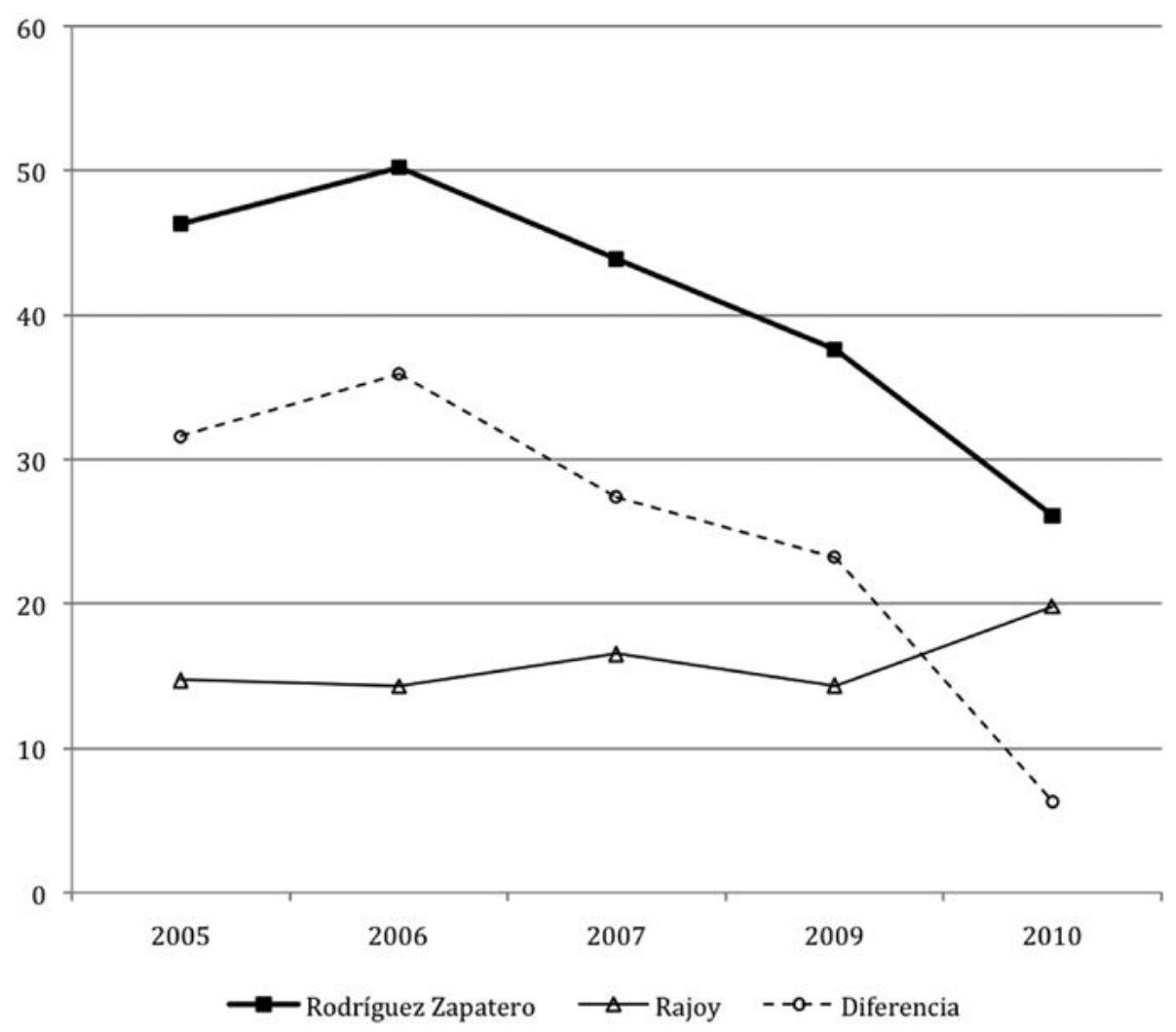

Fuente: CIS.es. 
partido de la oposición. Por otro lado, el PP se resintió por la forma en que perdió el poder en 2004, su exclusión política por el Pacto del Tinell en Cataluña primero y luego en el resto de Espańa, y llevó a cabo una oposición muy adversa con ataques políticos permanentes. Al final, Zapatero obtuvo un éxito táctico que le proporcionó apoyo electoral en los márgenes del electorado clásico del partido socialista, aunque algunas de sus políticas tuvieron fallos estratégicos que le alejaron del centro político. Una razón es que disponía de un completo control del grupo parlamentario socialista en el Congreso debido al predominio del Ejecutivo en el sistema político español, y mantuvo su apoyo a pesar de los desacuerdos internos, especialmente con el nuevo Estatuto de Cataluña. También fue el ganador indicutible de los debates sobre el estado de la nación en 2005, 2006 y 2007 (véase el gráfico 6).

\section{PRIMER MANDATO DE RODRÍGUEZ ZAPATERO: EL ANÁLISIS}

En general, su puntuación le clasifica como un líder de capital medio: 34 (2004), 32 (2006), 32 (2007) sobre 50 (véase la tabla 2). Su primer mandato estuvo marcado por una retórica vacua plena de buenas intenciones verbales, pero con una falta de sustancia política. Como es el caso con otros líderes, su fortaleza fue la debilidad de la oposición, con un partido antipático dirigido por un líder impopular.

\section{Tabla 2. Los valores del indice de capital de liderazgo de Rodriguez Zapatero, 2004-2008}

\begin{tabular}{clcccc}
\hline Criterios & \multicolumn{1}{c}{ Indicadores } & $\begin{array}{c}\text { Marzo } \\
\mathbf{2 0 0 4}\end{array}$ & $\begin{array}{c}\text { Abril } \\
\mathbf{2 0 0 6}\end{array}$ & $\begin{array}{c}\text { Abril } \\
\mathbf{2 0 0 7}\end{array}$ & Fuentes y medida \\
\hline Habilidades & & & & \\
\hline $\mathrm{C} 1 \quad \begin{array}{l}\text { 01.Visión política } \\
\text { y de las políticas } \\
\text { públicas }\end{array}$ & 3 & 3 & 3 & $\begin{array}{c}\text { Discurso y debate de } \\
\text { investidura. Legislación } \\
\text { innovadora y polarizadora }\end{array}$ \\
\hline $\mathrm{C} 1 \quad \begin{array}{l}\text { 02. Actuación } \\
\text { comunicativa }\end{array}$ & 4 & 4 & 4 & Gráfico 2 (CIS) \\
\hline $\mathrm{C} 2$ & $\begin{array}{l}\text { 03.Posición } \\
\text { personal en las } \\
\text { encuestas en } \\
\text { relación al líder de } \\
\text { la oposición }\end{array}$ & 4 & 3 & 3 & Gráfico 3 (CIS) \\
\hline
\end{tabular}




\begin{tabular}{clcccc}
\hline Criterios & \multicolumn{1}{c}{ Indicadores } & $\begin{array}{c}\text { Marzo } \\
\mathbf{2 0 0 4}\end{array}$ & $\begin{array}{c}\text { Abril } \\
\mathbf{2 0 0 6}\end{array}$ & $\begin{array}{c}\text { Abril } \\
\mathbf{2 0 0 7}\end{array}$ & Fuentes y medida \\
\hline C2 & $\begin{array}{l}\text { 04.Longevidad: } \\
\text { tiempo en el cargo }\end{array}$ & 4 & 4 & 4 & Completó los cuatro años \\
\hline C2 & $\begin{array}{l}\text { 05.Margen de la } \\
\text { (re)elección para } \\
\text { la dirección del } \\
\text { partido }\end{array}$ & 1 & 1 & 1 & Solo 9 votos \\
\hline
\end{tabular}

\begin{tabular}{|c|c|c|c|c|c|}
\hline \multicolumn{6}{|c|}{ Relaciones } \\
\hline $\mathrm{R} 1$ & $\begin{array}{l}\text { 06.Intención de } \\
\text { voto a su partido en } \\
\text { relación al resultado } \\
\text { de la elección más } \\
\text { reciente }\end{array}$ & 2 & 2 & 2 & Gráfico 4 (CIS) \\
\hline $\mathrm{R} 1$ & $\begin{array}{l}\text { 07. Niveles de } \\
\text { confianza pública } \\
\text { en el líder }\end{array}$ & 3 & 2 & 2 & Gráfico 5 (CIS) \\
\hline $\mathrm{R} 1$ & $\begin{array}{l}\text { 08.Probabilidad de } \\
\text { un desafío creíble a } \\
\text { su liderazgo en un } \\
\text { plazo de seis meses }\end{array}$ & 5 & 5 & 5 & $\begin{array}{l}\text { Candidato alternativo } \\
\text { inexistente }\end{array}$ \\
\hline \multicolumn{6}{|c|}{ Reputación } \\
\hline $\mathrm{R} 2$ & $\begin{array}{l}\text { 09. Habilidad } \\
\text { percibida para } \\
\text { configurar la } \\
\text { política del partido }\end{array}$ & 4 & 4 & 4 & $\begin{array}{c}\text { Ausencia de disidencia } \\
\text { interna }\end{array}$ \\
\hline $\mathrm{R} 2$ & $\begin{array}{l}\text { 10.Efectividad } \\
\text { parlamentaria } \\
\text { percibida }\end{array}$ & 4 & 4 & 4 & Gráfico 6 (CIS) \\
\hline & Total & 34 & 32 & 32 & \\
\hline
\end{tabular}

Fuente: elaboración propia.

El análisis revela tres áreas de pérdida o debilidad de su capital político. Tenía una visión política general y de las políticas públicas poco clara o inconsistente debido al predominio de las consideraciones tácticas en lugar de las estratégicas. Esto le hizo un líder propenso al riesgo, muy lejos de la phronesis aristotélica, que trató de implantar reformas políticas de mucho calado en 
áreas extremadamente delicadas sin suficiente apoyo político. De hecho, no fue capaz de construir un discurso político hegemónico al establecer la agenda política, incapaz de incorporar en ella las acciones gubernamentales. Además, tampoco fue hábil para producir una narración que diera sentido a toda la legislatura.

Resolvió muy bien su segunda área de pérdida de capital, su debilidad de origen, al haber sido elegido para el liderazgo del partido por un puñado de votos. Se deshizo de cualquier líder alternativo potencial o disidente. Su tercera debilidad, el descenso de la intención de voto a su partido con relación al resultado electoral de marzo de 2004, fue menos significativa, ya que se trata de una disminución típica del apoyo electoral debido a las acciones gubernamentales, pero al final ganó las siguientes elecciones generales en 2008 , tras una campaña muy personalizada.

\section{V. ¿̇CRISIS? ¿̇QUE CRISIS? LA GESTIÓN DE LA CRISIS ECONÓMICA}

En las elecciones generales de 2008, Rodríguez Zapatero fue reelegido con 11289335 votos (43,9\%) y 169 escaños (consigna: "Con Z de Zapatero») (Rico, 2010), siendo investido como presidente del Gobierno por los 169 votos del Grupo Socialista, necesarios para lograr la mayoría en la segunda votación de investidura (Montero y Lago, 2010). Recibió el voto negativo de 158 diputados (154 del PP, tres de ERC y uno de UPD) y 23 abstenciones (PNV, CiU, IU, ICV, BNG, CC y NaBai). La acción del Gobierno en su primer mandato le había valido una mejora en sus resultados electorales, pero un debilitamiento de su apoyo parlamentario, abandonado por IU, ERC - debido a su giro de 180 grados sobre el Estatuto de Autonomía de Cataluña, que Zapatero había negociado al final con CiU en 2006- y BNG. Así, afrontó su segundo mandato con otro Gobierno minoritario, pero con más debilidades y frente a una geometría variable de grupos que podrían respaldar sus iniciativas de política pública. Todo esto constituía una posición política mucho más vulnerable.

El segundo mandato de Rodríguez Zapatero (Olmeda y Colino, 2017: 210-216) giró en torno a la crisis económica desencadenada en Estados Unidos en 2007 con el estallido de la burbuja hipotecaria subprime y su posterior refinanciación con expansión global, dada la interrelación de las economías derivada de la globalización. El gran desafío que puso a prueba el capital político y de liderazgo de Zapatero en este segundo mandato fue indudablemente su capacidad para diagnosticar y gestionar las consecuencias domésticas de la crisis económica y financiera internacional que comenzó a afectar seriamente a la economía española después de su aparición. Sin embargo, las 
señales de la inminente crisis económica endógena fueron visibles ya desde 2006 con la creciente tasa de desempleo y la disminución del crecimiento del producto nacional bruto. La crisis financiera global agravó estos desequilibrios internos y provocó el estallido de la burbuja de la vivienda.

\section{C1. Visión y comunicación}

El debate televisivo preelectoral del 20 de febrero de 2008 entre Solbes, ministro de Economía de Zapatero, que también lo había sido con Felipe González, y Pizarro, los principales portavoces del PSOE y del PP en economía, respectivamente, fue muy significativo. Pizarro destacó los altos niveles de inflación, desempleo, déficit y deuda privada que caracterizaban a la economía española en ese momento. Solbes insistió en la necesidad de gastos sociales, así como en el mayor número de personas con empleo y la mayor tasa de crecimiento en comparación con 2003, cuando el PP estaba en el Gobierno. Según las diferentes encuestas realizadas, Solbes ganó ese debate (Juliana, 2008). Esta victoria televisada borró en cierto modo la crisis económica de la campańa y de la opinión pública, allanando el camino para la segunda victoria electoral de Zapatero.

En cualquier caso, de acuerdo con las promesas electorales de la campaña de 2008, ninguno de los principales partidos españoles anticipó correctamente el desarrollo de la economía en los meses siguientes a pesar de que se avecinaban evidentes problemas económicos: Zapatero había prometido un aumento del salario mínimo y las pensiones y pleno empleo, mientras que Rajoy había propuesto bajar los impuestos y aumentar las pensiones mínimas. En ese momento, la economía todavía estaba creciendo. Durante 2007 la economía española creció a una tasa del 3,7\%. A fines de ese año, incluso el Fondo Monetario Internacional compartía el relativo optimismo del Gobierno español, pronosticando una tasa de crecimiento económico del $2,7 \%$ en el PIB para 2008 (FMI, 2007: 8). Zapatero no admitió públicamente la existencia de la crisis económica hasta julio de $2008^{2}$. Esto demostró ser una devastadora falta de visión política y un gran error comunicativo.

Zapatero y sus ministros del área económica deberían haber tenido conocimiento de algunos datos perturbadores en el entorno económico internacional porque eran públicos mucho antes de las elecciones de marzo de 2008 (Buesa, 2010; Royo, 2009; Guindal 2012). Pero Zapatero tuvo una visión política y de las políticas públicas muy oscilante en su segundo mandato. El advenimiento de la crisis le tomó por sorpresa, como a casi todos los demás,

2 La Moncloa (2008). Entrevista al presidente del Gobierno en Antena 3, 8-7-2008. 
pero parece que no reaccionó a este cambio extremadamente importante en su contexto de liderazgo debido tanto a preocupaciones electorales como a factores de personalidad. Trató de intensificar su desempeńo comunicativo al explicar públicamente sus cambios en la política económica, pero no pudo construir una narración sin haber proporcionado previamente una base sólida de sentido sobre la crisis (véase el gráfico 2). Como subraya Chavero (2015: 232), «se produce un vacío comunicacional desde el Gobierno», al carecer de un encuadre alternativo.

En este segundo mandato podemos observar varias fases en el liderazgo de Zapatero que muestran una evolución paralela del contexto económico, su capital de liderazgo y su respuesta de gestión a la crisis en evolución. Para muchos observadores, esto podría considerarse como un caso típico de primer ministro con una pérdida gradual de capital político debido a su falta de visión política, al apoyo decreciente en su partido y al descenso de su popularidad (Colino y Olmeda, 2012). Al principio, negación de la crisis y normalidad, electoralmente triunfante y con control total de su partido, Zapatero ignoró los signos de la crisis, a pesar de que su oficina de asesores económicos y otros economistas independientes ya advertían de la gravedad de la situación (Guindal, 2012). En cambio, se enfrentó al comienzo de un nuevo período de gobierno con confianza, y llevó a cabo una reorganización del Gabinete con iniciativas discutibles y nuevos nombramientos ministeriales, pero con un renovado impulso político. Entonces, después de que el estallido de la crisis era ya evidente, Zapatero lo negó tanto en términos generales como respecto a las especificidades españolas reales, ignorando el consejo más ortodoxo y prudente del viceprimer ministro económico Solbes (Solbes, 2013), y siguiendo la recomendación de Sebastián, ministro de Industria y amigo cercano, que parecía minimizar la importancia de la situación, se refugió en la inacción (García Abad, 2012: 179-180).

En una segunda fase de difusión de la culpa y defensa de ideas económicas comunes y corrientes, Zapatero pareció retirarse al Palacio de la Moncloa, asumiendo la gestión de la crisis. Para ello cesó al más ortodoxo ministro de Economía y Hacienda, Solbes, y puso en su lugar a Salgado, una persona más receptiva a sus iniciativas (Guindal, 2012). También mediante la incorporación de los pesos pesados del partido en su reorganización del Gabinete de 2009, escondiéndose detrás de ellos. En esta fase, el paradigma dominante, incluso fugazmente, el neokeynesiano, era la preferencia ideológica del presidente y su partido, en oposición a un punto de vista un poco más liberal, como aconsejaba Solbes, el ministro recién despedido. Este estaba más preocupado por la sostenibilidad de las cuentas, en sintonía con los esfuerzos conjuntos del G-20 y la UE para estimular la demanda y superar las medidas extraordinarias y poco ortodoxas contra la recesión mundial (Buesa, 2010). 
Sin embargo, todavía no se había abierto la oportunidad para reformas estructurales y ajustes fiscales, por lo que incluso las comunidades autónomas, lideradas por Cataluña, pudieron atreverse a negociar y salirse con la suya con nuevos acuerdos de financiación territorial, a pesar de un momento tan grave, que representaba mayores obligaciones de gasto para el Gobierno central en once mil millones de euros (Buesa, 2010; Molina, 2012).

Una tercera fase se inaugura después de su viaje a Davos en enero de 2010, en el contexto de la crisis de la deuda soberana en Grecia y el monumental fallo de comunicación de sus asesores, que organizaron una sesión situándole entre Letonia y Grecia. Cuando a mediados de mayo los inversores internacionales se negaron a comprar deuda pública española, aunque sus rendimientos subían, líderes extranjeros como Merkel, Obama y Hu Jintao, temerosos de que una crisis de la deuda española pusiera en peligro al euro, le enviaron un claro mensaje de que Zapatero debería controlar el déficit público mediante la política fiscal. Desde ese momento, traicionando sus convicciones y consciente de cometer su suicidio político, Zapatero decidió culparse a sí mismo, eligiendo desempeñar el papel de estadista e implantando recortes de gasto público sin precedentes. Esta acción, sin embargo, aunque para algunos observadores y sus partidarios representó la salvación de España de la bancarrota y el rescate, pareció infructuosa frente a los mercados y a la desconfianza de la opinión pública, debido a la falta de explicaciones convincentes sobre el giro en la política económica.

Tras haber declarado obstinadamente que no permitiría una solución antisocial a la crisis económica, con la presión de los mercados financieros y la de los líderes europeos y mundiales, pareció haber perdido el control de la situación. Por un lado, la retórica keynesiana se reemplazó rápidamente por una nueva fe en los beneficios de la consolidación fiscal y la competitividad, lo que provocó el riesgo de intervención causada por una deuda insostenible. En agosto, Zapatero recibió una carta que mantuvo secreta de Trichet, entonces presidente del Banco Central Europeo, exigiendo reformas adicionales (Rodríguez Zapatero, 2013: 405-408). De repente, los sindicatos y los empleadores, reemplazados por un foro de dirigentes del IBEX, dejaron de ser los socios para las reformas del mercado laboral o de las pensiones y se convocó una huelga general en septiembre de 2010 (Molina, 2012; Rodríguez Zapatero, 2013). Esto se consideró una metamorfosis radical y una tremenda pérdida de capital político que el propio Zapatero describió en el Congreso como un cambio de opinión causado "por las circunstancias, no por las convicciones»" También en sus propias palabras: «Ese día, la experiencia de Gobierno te dicta

3 Diario de Sesiones del Congreso de los Diputados (2010). Pleno y Diputación Permanente. IX Legislatura, núm. 177. Disponible en: https://bit.ly/3qSRbZw. 
que, una vez tomada la decisión, la tienes que defender con todas sus consecuencias», declaró en una entrevista (Moreno, 2010).

Por último, la fase agonizante de su liderazgo se produjo con el anuncio en el Comité Federal del PSOE el 2 de abril de 2011, de que no sería candidato a la reelección, aceptando toda la responsabilidad y la culpa, y el posible crédito, por el impopular giro de la política económica. Debe recordarse que en mayo de 2011 el movimiento social de los indignados había surgido en varias ciudades con muchos jóvenes españoles soliviantados por las decisiones de Zapatero. En esta etapa, Zapatero desapareció en cierta medida del primer plano de la escena para centrar toda la atención en el nuevo candidato Pérez Rubalcaba, su vicepresidente del Gobierno y exministro con Felipe González. Al final de su mandato regresó brevemente para acordar con el líder de la oposición Rajoy la enmienda del art. 135 de la Constitución española para afianzar la estabilidad presupuestaria y tratar de calmar a los mercados crediticios internacionales con las sutiles sugerencias del BCE, la carta de Trichet, y la canciller alemana, Merkel.

\section{C2. Sondeos, longevidad y elección}

Como se muestra en el gráfico 2, en este mandato Zapatero no pudo mantener su ventaja habitual sobre Rajoy en la valoración personal de las encuestas. Al principio de su mandato estuvo por encima de un punto porcentual un par de veces, pero luego comenzó un declive constante y fue superado por Rajoy en 2011. Zapatero no pudo terminar su mandato y convocó elecciones anticipadas para noviembre de 2011. Uno de los componentes esenciales de cualquier evaluación del capital de liderazgo de Zapatero es la ausencia de un candidato alternativo interno en sus dos mandatos, una vez que alcanzó el poder primero en el partido y luego en el Gobierno.

\section{R1. Sondeos, confianza y desafío}

El colapso electoral del PSOE se muestra en el gráfico 3. El punto de inflexión aparece entre 2009 y 2010, y desde julio de 2010 el apoyo electoral al PP crece constantemente hasta justo antes de las elecciones de noviembre de 2011. Al final de este período, el PSOE había perdido 26,0 puntos porcentuales en la intención directa de voto.

El nivel de confianza pública en Rodríguez Zapatero se derrumbó desde el comienzo del período en general, perdiendo 28,8 puntos porcentuales. La desconfianza hacia él crece desde el $51,1 \%$ en abril de 2008, hasta $81,5 \%$ en abril de 2011 (véase el gráfico 4). No hay pérdida similar en la serie temporal relativa a los presidentes del Gobierno españoles en el régimen democrático. 


\section{R2. Políticas públicas y Parlamento}

Cuando Zapatero se vio obligado a cambiar hacia una política de austeridad ordoliberal más consecuente en mayo de 2010, pudo hacerlo sin ninguna oposición interna significativa en su partido o grupo parlamentario. Pero las dudas y las oscilaciones de los dirigentes eran constatables y hubo varios ejemplos de errores evidentes de coordinación entre el Gobierno y el grupo parlamentario, debido a su situación minoritaria y la necesidad de negociar con diferentes socios para distintas cuestiones, exponiendo la fragilidad del liderazgo de Zapatero.

El primer ejemplo se produjo durante la negociación de las mociones posteriores al debate sobre el estado de la nación en mayo de 2009, cuando los grupos PSOE y CiU acordaron una resolución que incluía la negociación de la reforma del mercado laboral con los sindicatos. El texto hablaba de incluir a las entidades privadas en la reubicación de los desempleados para "acabar con la dualidad del mercado laboral» entre empleos permanentes y temporales, esto es, estudiar un nuevo tipo de contrato. Era la primera vez que el PSOE aceptaba esta reforma, incluso condicionada a un acuerdo social previo (Garea y Díez, 2009). Sin embargo, el día siguiente el grupo parlamentario socialista rompió ese acuerdo con $\mathrm{CiU}$ en el último minuto debido a la presión de la izquierda y los sindicatos.

Otro ejemplo fue el anuncio de un giro a la izquierda en la política impositiva y su eliminación seis horas después, esta vez bajo la presión de CiU. El Partido Socialista y la izquierda llegaron a un acuerdo de seis puntos sobre política fiscal para implantar en 2010. El giro a la izquierda significaba impuestos más altos para los mayores ingresos, nuevos impuestos relacionados con el medio ambiente y la rectificación de algunos principios preciados del Gobierno de Zapatero, como los beneficios lineales y las deducciones fiscales. El portavoz de CiU habló de inclinaciones izquierdistas en el vicepresidente del Gobierno (Garea, 2009). Pese a todo ello, venció a Rajoy en los debates del estado de la nación en 2009 y 2010 (véase el gráfico 5).

\section{LA GESTIÓN DE LA CRISIS ECONÓMICA DE ZAPATERO, 2008-2011: EL ANÁLISIS}

En general, las puntuaciones de Zapatero -33 (2008), 25 (2010) y 18 (2011) sobre 50 (véase la tabla 3) —, lo clasifican como un líder de capital de liderazgo medio-alto al comienzo de su segunda legislatura, pero terminando como un líder con capital bajo. Su segundo mandato estuvo marcado por su estrategia de negación de la crisis desde el debate entre el PSOE y el PP en la campaña electoral de 2008. Esta estrategia continuó después de la victoria 


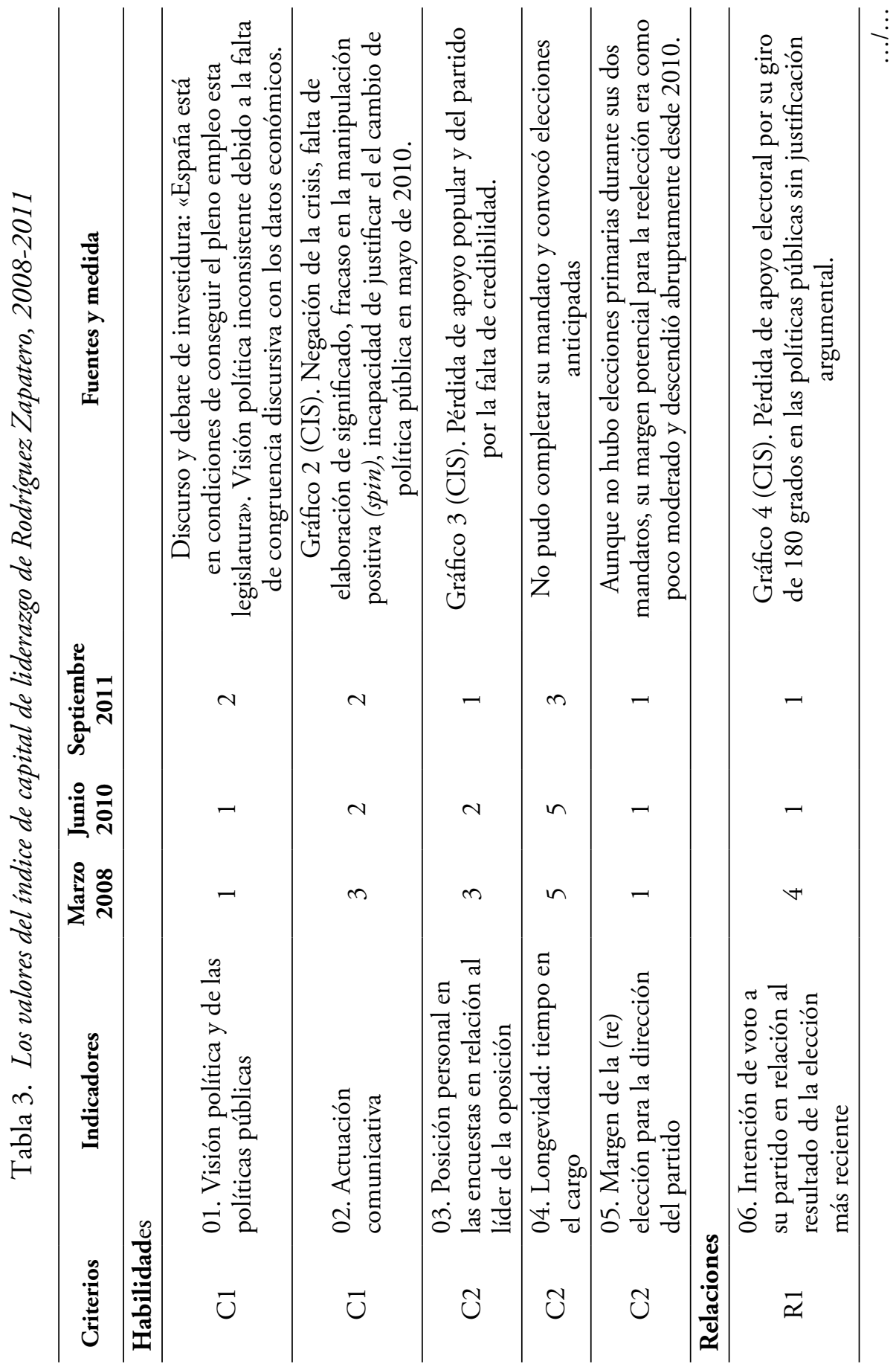




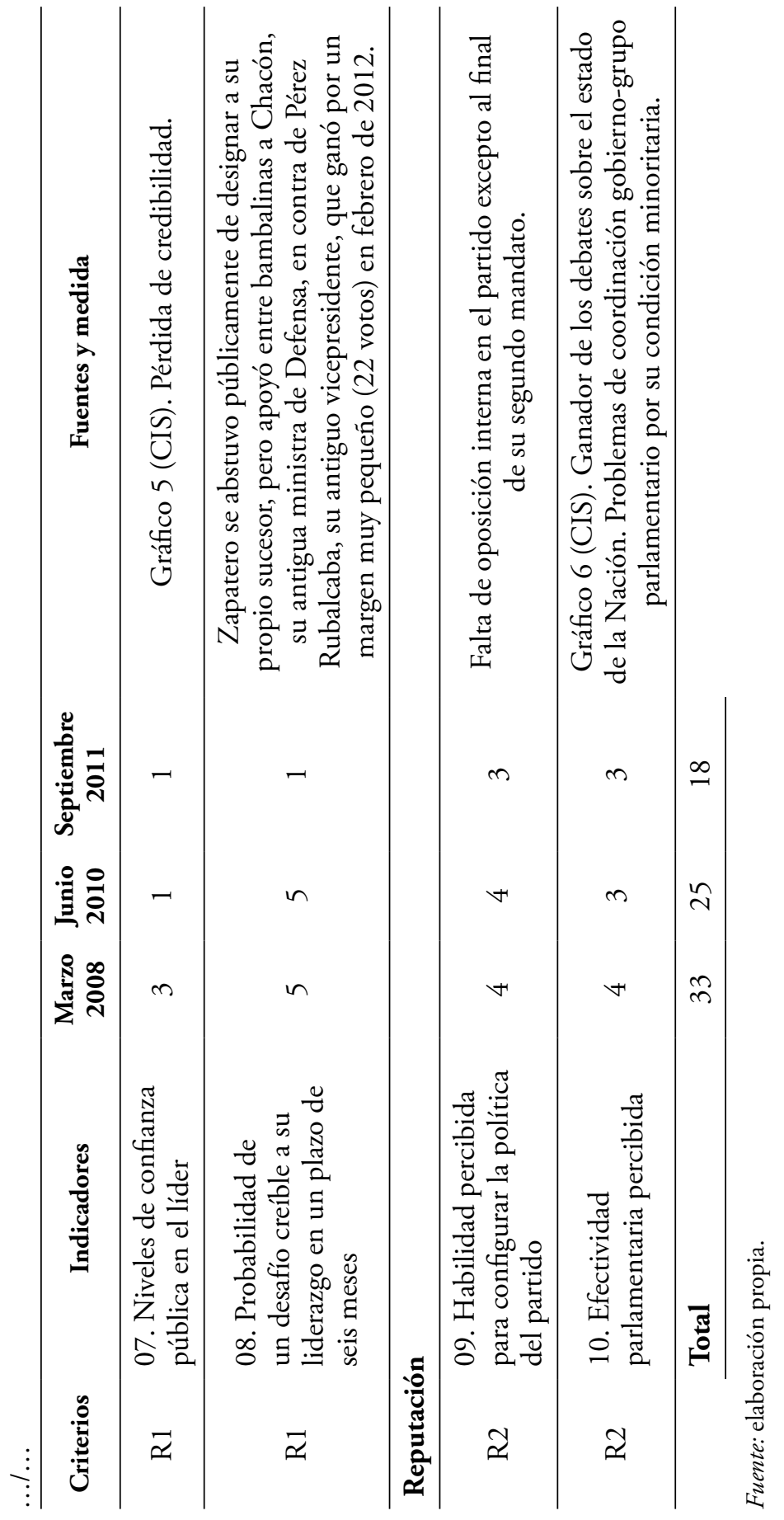


electoral porque Zapatero y el Gobierno del PSOE se negaron a reconocer o confirmar una verdad incómoda e inconveniente, pero la información estaba allí. La posición de negar o minimizar la existencia de la crisis económica puso la carga de la prueba en manos de la oposición política, pero disminuyó el espacio de maniobra retórica.

Posteriormente, trató de culpar de la situación a las "fuerzas externas», exclusivamente, hablando de tiempos «sin precedentes», de la peor crisis «desde la Gran Depresión» de la década de 1930. Para prevenir el pánico, él y sus ministros económicos hablaron de la fuerte posición del país para afrontar la crisis, los «sólidos fundamentos» de la economía española y de su sistema bancario y los inminentes «brotes verdes» que nunca llegaron. También hubo una tendencia a moralizar, primero contra el sistema bancario estadounidense, y luego contra los bancos codiciosos y los banqueros en general, intentanto evocar acordes de la memoria anticapitalista. Los ciudadanos notaron, algunos directamente en su propia carne, que esas declaraciones fueron contradichas por los hechos. La oposición política solo tuvo que dejar pasar el tiempo.

Hubo un problema con esta mala gestión inicial de la crisis económica, atribuible no solo al calendario electoral, sino a un sesgo de su personalidad que algunos observadores denominaron como «optimismo patológico» (González, 2011), que podemos relacionar con lo que Owen y Davidson (2009: 1396-1406) han denominado «síndrome de hibris» dentro de una personalidad narcisista, con excesivos orgullo y confianza en sí mismo junto con un abrumador desprecio por los demás, una negativa a escuchar consejos, un comportamiento impetuoso, dominado por la impulsividad y la imprudencia. Cuando Zapatero necesitó tomar medidas extraordinarias para evitar un procedimiento de rescate abierto como sucedió en otros países europeos, hubo un fallo en cascada. Como no había proporcionado un sentido apropiado para la crisis, basado en un diagnóstico correcto de la situación, no pudo desarrollar una elaboración de significado apropiada — proporcionando una narración persuasiva para el público de lo que estaba sucediendo, por qué, qué se podía hacer al respecto, cómo y por quién-. En un análisis comparativo independiente sobre el desempeño de los primeros ministros en la crisis del euro, Van Esch y Swinkels (2015: 1212) tipifican a Zapatero como poseedor de una complejidad cognitiva promedio más una alta confianza en sí mismo, clasificándolo como cerrado a la información y teniendo, por lo tanto, una menor sensación de urgencia e incertidumbre para la elaboración de significado. Sus decisiones cayeron en medio de un vacío de significación y sentido con la pérdida de credibilidad presidencial, y la necesidad de responsabilizarlo ocupó el espacio discursivo de la opinión pública ('t Hart y Tindall, 2009: 6-7). La rendición de cuentas se materializó más tarde en los desastrosos resultados electorales de su partido, que perdió 4285824 votos y 59 escaños. 
Puede decirse que Zapatero no ha sido capaz de cumplir las tareas de liderazgo en una crisis económica, aunque no haya sido el único líder europeo en esta circunstancia (Boin et al., 2005; Boin et al., 2012; Masters y 't Hart, 2012).

El análisis de las dimensiones de ICL en este caso revela dos áreas principales de pérdida o debilidad del capital de liderazgo. El primero es el desempeño comunicativo y la valoración personal de las encuestas para reconocer un cambio importante en su contexto político. Debido a esta falta de visión política, no podía darle sentido a la crisis que se avecinaba, lo que complicaba su desempeño comunicativo porque no era capaz de proporcionar significado a la situación y para explicar su cambio de política y las reformas impopulares. Pero las principales pérdidas vinieron de sus relaciones con el partido y su reputación. Como resultado, hubo una aguda pérdida de capital de liderazgo y de credibilidad de Zapatero como dirigente, y posteriormente su partido se colapsó en las urnas.

\section{CONCLUSIÓN: EVOLUCIÓN Y COMPARACIÓN DEL CAPITAL DE LIDERAZGO DE RODRÍGUEZ ZAPATERO}

Este artículo ha tratado de aclarar explicativamente cómo la gestión de una crisis financiera afectó a la trayectoria del capital de liderazgo de Zapatero, que comenzó con un capital relativamente medio-alto en su primera legislatura, pero que perdió muy rápidamente y de manera sustancial en interacción con su gestión de la crisis (véase la tabla 4).

Tabla 4. Instantáneas del capital de liderazgo de Rodriguez Zapatero

\begin{tabular}{lc}
\hline & Puntuación del ICL \\
\hline Rodríguez Zapatero I & \\
\hline Marzo 2008 & 34 \\
Abril 2006 & 32 \\
Abril 2007 & 32 \\
\hline Rodríguez Zapatero II \\
\hline Marzo 2008 \\
Junio 2010 & 33 \\
Septiembre 2011 & 25 \\
\hline
\end{tabular}

Fuente: elaboración propia. 
Esta comparación de las puntuaciones del ICL de Zapatero en el contexto de la gestión de la crisis económica nos da algunas claves interesantes para tratar de explicar cómo y por qué el capital de liderazgo se ve afectado y afecta a la gobernación y específicamente por las respuestas a la crisis. Zapatero perdió su capital de liderazgo debido a su gestión de esta (véase la tabla 3). La pérdida de capital de liderazgo se produjo sobre todo en el desempeño de sus habilidades inspiradoras y persuasivas y en sus relaciones con la opinión pública (aumento de la desconfianza y pérdida de apoyo electoral), con el desconcierto subsiguiente de su partido y de sus apoyos electorales.

La trayectoria de Zapatero es típica de un líder meteórico (Bennister et al., 2017). Hay que tener en cuenta que Zapatero se enfrentó desde el poder a los tiempos políticos del comienzo de la Gran Recesión. Pero no pudo proporcionar sentido y dar un encuadramiento (framing) de la crisis debido al deterioro de su visión política y la consiguiente falta de diagnóstico, los cálculos electorales, su arrogancia (hibris) y los problemas de reputación. La comparación de ambos mandatos arroja seguramente algo de luz sobre los límites de la gobernación en la democracia parlamentaria en los países del sur de Europa dentro de la zona euro y sobre los posibles usos del ICL para el estudio del papel del liderazgo y sus resultados.

Creo haber mostrado la posible utilidad del concepto de capital de liderazgo y de su operacionalización mediante el ICL como instrumento analítico para estudiar el desempeño de un líder político como el presidente del gobierno en España. Su aplicación sistemática a los distintos presidentes, nacionales o regionales, del periodo democrático permitiría iluminar la paulatina presidencialización, personalización y mediatización de nuestro sistema político-administrativo en sus distintos niveles de gobierno y sus respectivos liderazgos con una óptica más matizada que las habituales preguntas y respuestas sobre popularidad, conocimiento y valoración de los líderes políticos. Aunque el capital de liderazgo proporciona una perspectiva de interés, una evaluación más completa y matizada de la gobernación de un presidente dado requeriría también el análisis del éxito o el fracaso de las principales políticas públicas impulsadas por él, más allá de la mera promulgación de leyes, como es frecuente.

\section{Bibliografía}

Alcántara, M. (2017). La carrera política y el capital político. Convergencia. Revista de Ciencias Sociales, 73, 187-204.

Almond, G. (1969). Political Development. Analytical and Normative Perspectives. Comparative Political Studies, 1 (4) 447-469. Disponible en: https://doi.org/10.1177/0010 41406900100401.

Álvarez, J. L. (2014). Los presidentes españoles. Personalidad y oportunidad, las claves del liderazgo político. Madrid: LID. 
Bennister, M. (2012). Prime Ministers in Power. Political Leadership in Britain and Australia. Basingstoke: Palgrave. Disponible en: https://doi.org/10.1057/9780230378445.

Bennister, M., 't Hart, P. y Worthy, B. (2015). Assessing the Authority of Political Office-Holders, the Leadership Capital Index. West European Politics, 38, 3, 417-440. Disponible en: https://doi.org/10.1080/01402382.2014.954778.

Bennister, M., Worthy, B. y 't Hart, P. (eds.) (2017). The Leadership Capital Index. A New Perspective on Political Leadership. Oxford: Oxford University Press. Disponible en: https:// doi.org/10.1093/oso/9780198783848.001.0001.

Blondel, J. (1987). Political Leadership. Toward a General Analysis. London: Sage.

Boin, A., 't Hart, P., Stern, E. y Sundelius, B. (2005). The Politics of Crisis Management, Public Leadership under Pressure. Cambridge: Cambridge University Press. Disponible en: https://doi.org/10.1017/CBO9780511490880.

Boin, A., Van Esch, F. (2012). Polititical Leadership in Times of Crisis, Comparing Leader Responses to Financial Turbulence. En L. Helms (ed.). Comparative Political Leadership (pp. 119-141). Houndmills: Palgrave Macmillan. Disponible en: https://doi. org/10.1057/9781137264916_6.

Bosco, A. y Sánchez-Cuenca, I. (2009). La España de Zapatero. Años de cambios, 2004-2008. Madrid: Fundación Pablo Iglesias.

Bourdieu, P. (1986). The forms of capital. En J. Richardson (comp.). Handbook of Theory and Research for the Sociology of Education (pp. 241-258). New York: Greenwood.

Bourdieu, P. (1991). Language and Symbolic Power. Cambridge: Polity Press.

Brown, A. (2014). The Myth of the Strong Leader. Political Leadership in Modern Times. New York: Basic Books.

Buesa, M. (2010). La crisis de la economía fragmentada. Economía politica de la era Zapatero. Madrid: Ediciones Encuentro.

Burns, J. MacGregor (1978). Leadership. New York: Harper and Row.

Campillo, Ó. (2001). Zapatero. Madrid: La Esfera de los Libros.

Campmany, J. (2005). El efecto ZP. 1000 días de campaña para llegar a la Moncloa. Barcelona: Planeta.

Chamorel, P. (2003). The Comparative Leadership Styles of French and American Presidents. Leadership Review. Disponible en: www.leadershipreview.org/2003summer/article2_ summer_2003.asp

Chavero, P. (2015). Prensa y politica en tiempos de crisis, estudio de la legislatura 2008-2011. Madrid: Centro de Investigaciones Sociológicas.

Colino, C. y Olmeda, J. A. (2012). El estilo de gobierno y de liderazgo. En C. Colino y R. Cotarelo (comps.). España en crisis. Balance de la segunda legislatura de Rodríguez Zapatero (pp. 75-108). Valencia: Tirant lo Blanch.

Collado, F. y Jiménez, J. F. (2011). Liderazgo y discurso político de Rodríguez Zapatero ante la situación económica de 2008. Oralia, 14, 293-314.

Collado, F. y Jiménez, J. F. (2012). Discursos políticos ante la crisis económica: estudio del líder del PSOE. Barataria. Revista Castellano-Manchega de Ciencias Sociales, 14, 41-57.

Collado F., Jiménez, J. F., Entrena, F. (2016). El liderazgo político en las democracias representativas: propuesta de análisis desde el constructivismo estructuralista. Revista 
Mexicana de Ciencias Politicas y Sociales, 61 (228), 57-90. Disponible en: https://doi. org/10.1016/S0185-1918(16)30040-X.

Delgado, S. y Cazorla, A. (2017). El Partido Socialista Obrero Español: de la hegemonía a la decadencia. Revista Española de Ciencia Política, 44, 247-273. Disponible en: https:// doi.org/10.21308/recp.44.10.

Elgie, R. (1995). Political Leadership in Liberal Democracies. London: Macmillan. Disponible en: https://doi.org/10.1007/978-1-349-24216-0.

Elgie, R. (2015). Studying Political Leadership. Foundations and Contending Accounts. Houndmills: Palgrave Macmillan. Disponible en: https://doi.org/10.1007/978-1-137-34708-4.

Esch, F. van y Swinkels, M. (2015). How Europe's Political Leaders Made Sense of the Euro Crisis, The Influence of Pressure and Personality. West European Politics, 38 (6), 12031225. Disponible en: https://doi.org/10.1080/01402382.2015.1010783.

Field, B. N. (comp.) (2011). Spain's 'second transition?? The Socialist government of Jose Luis Rodríguez Zapatero. New York: Routledge.

FMI (Fondo Monetario Internacional) (2007). World Economic Outlook, octubre. Disponible en: https://bit.ly/3ofvQrC.

French, R. D. (2011). Political capital. Representation, 47 (2), 215-230. Disponible en: https:// doi.org/10.1080/00344893.2011.581086.

García Abad, J. (2010). El Maquiavelo de León. Cómo es en realidad Zapatero. Madrid: La Esfera de los Libros.

Garea, F. (2009). El PSOE anuncia un giro fiscal a la izquierda y lo retira a las seis horas. El País, 24-6-2009. Disponible en: https://bit.ly/3oovH5v.

Garea, F. y Díez, A. (2009). El PSOE acuerda la mayoría de sus resoluciones con el Grupo Mixto. El Pais, 19-5-2009. Disponible en: https://bit.ly/3iKdoWY.

González, S. (2011). Lágrimas socialdemócratas. El desparrame sentimental del zapaterismo. Madrid: La Esfera de los Libros.

González Hernández, J. C. (2005). Notas sobre la idea de capital político. Reflexiones críticas en torno a las teorías del capital social y diseńo de conceptos alternativos. En J. Montabes y J. Cazorla (comps.). Estructura y procesos sociales. Homenaje a José Cazorla (pp. 133-181). Madrid: Centro de Investigaciones Sociológicas.

González Rodríguez, J. J. (2008). Los medios en la democracia avanzada. ¿Hacia una democracia de audiencia? En J. J. González, M. Requena (comps.). Tres décadas de cambio social en España (pp. 345-381). Madrid: Alianza.

González Rodríguez, J. J. y Bouza, F. (2009). Las razones del voto en la España democrática 1977-2008. Madrid: Catarata.

González Rodríguez, J. J. y Olmeda, J. A. (2012). El sistema mediático en tiempos de Rodríguez Zapatero: un bucle melancólico. En C. Colino y R. Cotarelo (comps.). España en crisis. Balance de la segunda legislatura de Rodríguez Zapatero (pp. 311-330). Valencia: Tirant lo Blanch.

Greenstein, F. I. (2000). The Presidential Difference. Leadership Style from FDR to Clinton. New York: The Free Press.

Guindal, M. (2012). Los días que vivimos peligrosamente. La trastienda de la peor crisis económica que ha vivido España. Barcelona: Planeta. 
Hallin, D. C. y Mancini, P. (2004). Comparing Media Systems. Three Models of Media and Politics. New York: Cambridge University Press. Disponible en: https://doi.org/10.1017/ CBO9780511790867.

Helms, L. (2005). Presidents, Prime Ministers and Chancellors. Executive Leadership in Western Democracies. Houndmills: Palgrave. Disponible en: https://doi.org/10.1057/ 9780230502918.

Helms, L. (2008). Governing in the Media Age: The Impact of the Mass Media on Executive Leadership in Contemporary Democracies. Government and Opposition, 43 (1), 26-54. Disponible en: https://doi.org/10.1111/j.1477-7053.2007.00242.x.

Helms, L. (comp.) (2012). Comparative Political Leadership. Houndmills: Palgrave Macmillan. Disponible en: https://doi.org/10.1057/9781137264916.

Jaén, E. y Escudier, J. C. (2007). Zapatero «el rojo». Madrid: Foca.

Jiménez, J. F. y Collado, F. (2011). Contexto político y semblanza biográfica de José Luis Rodríguez Zapatero. Espacios Públicos, 14 (31), 136-157.

Jiménez, J. F. y Delgado, S. (comps.) (2016). Political Leadership in the Spanish Transition to Democracy (1975-1982). New York: Nova Science Publishers.

Jiménez, J. F. y Peña, J. A. (2018). El papel cambiante del liderazgo: de la Transición a un «tiempo nuevo». En F. J. Llera, M. Baras y J. Montabes (comps.). Las elecciones generales de 2015 y 2016. (pp. 351-377). Madrid: Centro de Investigaciones Sociológicas.

Joignant, A. (2012). Habitus, campo y capital. Elementos para una teoría general del capital político. Revista Mexicana de Sociología, 74 (4), 587-618.

Joignant, A. (2019). Acting Politics. A Critical Sociology of the Political Field. Abingdon: Routledge. Disponible en: https://doi.org/10.4324/9781315211138.

Juliana, E. (2008). Solbes gana el primer debate. La Vanguardia, 22-2-2008. Disponible en: https://bit.ly/3iLG0PS.

Kane, J. (2001). The Politics of Moral Capital. Cambridge: Cambrdge University Press. Disponible en: https://doi.org/10.1017/CBO9780511490279.

Linz, J. J. (2009 [1993]). El liderazgo innovador en la transición a la democracia y en una nueva democracia. En J. R. Montero y Th. J. Miley (eds.). Obras escogidas. Democracias: quiebras, transiciones y retos (pp. 391-425). Madrid: Centro de Estudios Políticos y Constitucionales.

López, E. J. (2002). The Legislator as Political Entrepreneur: Investment in Political Capital. The Review of Austrian Economics, 15 (2/3), 211-228. Disponible en: https://doi. org/10.1023/A:1015770705872.

Martí, J. L. y Pettit, P. (2010). A political philosophy in public life: civic republicanism in Zapatero's Spain. Princeton: Princeton University Press. Disponible en: https://doi. org/10.1515/9781400835058.

Masters, A. y 't Hart, P. (2012). Prime ministerial Rhetoric and Recession Politics, Meaning Making in Economic Crisis Management. Public Administration, 90 (3), 759-780. Disponible en: https://doi.org/10.1111/j.1467-9299.2011.01966.x.

Mazzoleni, G. (2010). La comunicación politica. Madrid: Alianza.

Mazzoleni, G. (2008). Populism and the Media. En D. Albertazzi y D. McDonnell (comps.). Twenty-First Century Populism: The Spectre of Western European Democracy (pp. 49-64). New York: Palgrave Macmillan. 
Méndez, M. (2006). Turning the Page: Crisis and Transformation of the Spanish Socialist Party. South European Society and Politics, 11 (3-4), 419-437. Disponible en: https://doi. org/10.1080/13608740600856447.

Molina, I. (2012). Gobierno y desgobierno de la economía, las políticas de respuesta a la crisis. En C. Colino y R. Cotarelo (comps.). España en crisis. Balance de la segunda legislatura de Rodriguez Zapatero (pp. 49-73). Valencia: Tirant lo Blanch.

Montero, J. R. y Lago, I. (comps.) (2010). Elecciones generales 2008. Madrid: Centro de Investigaciones Sociológicas.

Montero, J. R., Lago, I. y Torcal, M. (comps.) (2007). Elecciones generales 2004. Madrid: Centro de Investigaciones Sociológicas.

Montero, J. R. y Lago, I. (2007). Del 11-M al 14-M: terrorismo, gestión del gobierno y rendición de cuentas. En J. R. Montero, I. Lago y M. Torcal (comps.) (2007). Elecciones generales 2004 (pp. 169-204. Madrid: Centro de Investigaciones Sociológicas.

Moreno, J. (2010). Convocaré a las 25 grandes empresas del país para acelerar la recuperación. El País, 21-11-2010.

Nash, E. et al. (2008). The Reign of Spain: European champions (of nearly everything). The Independent. 1-7-2008.

Natera, A. (2001). El liderazgo político en la sociedad democrática. Madrid: Centro de Estudios Políticos y Constitucionales.

Olmeda, J. A. (2008). A reversal of fortune: blame games and framing contest after the 3/11 terrorist attacks in Madrid. En A. Boin, A. McConnell y P. 't Hart (comps.). Governing after Crisis. The Politics of Investigation, Accountability and Learning (pp. 62-84). Cambridge: Cambridge University Press. Disponible en: https://doi.org/10.1017/ CBO9780511756122.003.

Olmeda, J. A. y Colino, C. (2017). Leadership Capital in a Protracted Crisis: Spanish Prime Ministers Compared. En M. Bennister, B. Worthy y P. 't Hart (eds.). The Leadership Capital Index. A New Perspective on Political Leadership (pp. 207-225). Oxford: Oxford University Press. Disponible en: https://doi.org/10.1093/oso/ 9780198783848.003 .0011 .

Owen, D. y Davidson, J. (2009). Hibris syndrome, An acquired personality disorder? A study of US Presidents and UK Prime Ministers over the last 100 years. Brain, 132, 13961406. Disponible en: https://doi.org/10.1093/brain/awp008.

Papell, A. (2008). Zapatero 2004-2008. La legislatura de la crispación. Madrid: Foca.

Picarella, L. (2009). Presidencialización y personalización en el sistema político español, 19752008. Enfoques, 7 (11), 515-544.

Picarella, L. (2014). De la transición al zapaterismo: la evolución del sistema politico español entre presidencialización y personalización. Bogotá: Universidad Católica de Colombia.

Poguntke, T. y Webb, P. (2005). The presidentialization of politics: a comparative study of modern. Oxford: Oxford Universtiy Press. Disponible en: https://doi.org/10.1093/019 9252017.001 .0001$.

Rahat, G. y Kenig, O. (2018). From Party Politics to Personalized Politics? Party Change and Political Personalization in Democracies. Oxford: Oxford University Press. Disponible en: https://doi.org/10.1093/oso/9780198808008.001.0001. 
Rhodes, R. A. W. y 't Hart, P. (comps.) (2014). The Oxford Handbook of Political Leadership. Oxford: Oxford University Press. Disponible en: https://doi.org/10.1093/oxfo $\mathrm{rdhb} / 9780199653881.001 .0001$.

Rico, G. (2007). «¡No nos falles!» Los candidatos y su peso electoral. En J. R. Montero, I. Lago, M. Torcal (comps.). Elecciones generales 2004 (pp. 331-359). Madrid: Centro de Investigaciones Sociológicas.

Rico, G. (2009). Líderes políticos, opinión pública y comportamiento electoral en España. Madrid: Centro de Investigaciones Sociológicas.

Rico, G. (2010). El impacto de los líderes en las elecciones de 2008 y más allá. En J. R. Montero y I. Lago (comps.). Elecciones generales 2008 (pp. 303-329). Madrid: Centro de Investigaciones Sociológicas.

Rodríguez Aizpeolea, L. (2004). Ciudadano Zapatero. Madrid: Espejo de Tinta.

Rodríguez Zapatero, J. L. (2013). El dilema. 600 días de vértigo. Barcelona: Planeta.

Royo, S. (2009). After the Fiesta, The Spanish Economy Meets the Global Financial Crisis. South European Society and Politics, 14 (1) 19-34. Disponible en: https://doi.org/ 10.1080/13608740902995828.

Sánchez-Cuenca, I. (2012). Años de cambios, años de crisis. Ocho años de gobiernos socialistas, 2004-2011. Madrid: Catarata.

Santamaría, J. (2007). Las elecciones generales de 2004 en su contexto. En J. R. Montero, I. Lago y M. Torcal (comps.). Elecciones generales 2004 (pp. 31-63). Madrid: Centro de Investigaciones Sociológicas.

Skowronek, S. (1997) [1993]. The Politics Presidents Make. Leadership from John Adams to Bill Clinton. Cambridge (Mass.): Harvard University Press.

Skowronek, S. (2008). Presidential Leadership in Political Time. Reprise and Reappraisal. Lawrence: University Press of Kansas.

Solbes, P. (2013). Recuerdos. 40 años de servicio público. Barcelona: Deusto.

Strangio, P., 't Hart, P. y Walter, J. (eds.) (2013). Understanding Prime-Ministerial Performance. Comparative Perspectives. Oxford: Oxford University Press. Disponible en: https://doi. org/10.1093/acprof,oso/9780199666423.001.0001.

't Hart, P. (2014). Understanding Public Leadership. London: Palgrave. Disponible en: https:// doi.org/10.1007/978-1-137-45057-9.

't Hart, P. y Tindall, K. (2009). Framing the Global Economic Downturn, Crisis Rhetoric and the Politics of Recessions. Canberra: Australian National University E Press. Disponible en: https://doi.org/10.26530/OAPEN_459240.

't Hart, P. y Uhr, J. (2008). Public Leadership. Perspectives and Practices. Canberra: The Australian National University Press. Disponible en: https://doi.org/10.26530/OAPEN_459473.

Theakston, K. (2011). Gordon Brown as prime minister. Political skills and leadership style. British Politics, 6 (1) 78-100. Disponible en: https://doi.org/10.1057/bp.2010.19.

Theakston, K. (2017). What makes for an effective British prime minister? Quaderni Di Scienza Politica, 14 (2), 227-249.

Toro, S. de (2007). Madera de Zapatero. Retrato de un presidente. Madrid: RBA.

Valenzuela, J. (2007). Viajando con ZP. Barcelona: Debate.

Zarzalejos, J. A. (2011). La sonrisa de Julia Roberts. Zapatero y su época. Barcelona: Chronica. 